ALINE SIMÕES DE ALENCASTRO

ESTIMULAÇÃO TRANSCRANIANA POR CORRENTE CONTÍNUA: EFEITOS SOBRE A MEMÓRIA OPERACIONAL DE IDOSOS 


\author{
UNIVERSIDADE DE BRASÍLIA \\ FACULDADE DE CIÊNCIAS DA SAÚDE \\ PROGRAMA DE PÓS-GRADUAÇÃO EM CIÊNCIAS DA SAÚDE
}

ALINE SIMÕES DE ALENCASTRO

ESTIMULAÇÃO TRANSCRANIANA POR CORRENTE CONTÍNUA: EFEITOS SOBRE A MEMÓRIA OPERACIONAL DE IDOSOS

Dissertação apresentada como requisito parcial para a obtenção do Título de Mestre em Ciências da Saúde pelo Programa de PósGraduação em Ciências da Saúde da Universidade de Brasília.

Orientador: Prof. Dr. Joaquim Pereira Brasil Neto

BRASÍLIA 


\title{
ESTIMULAÇÃO TRANSCRANIANA POR CORRENTE CONTÍNUA: EFEITOS SOBRE A MEMÓRIA OPERACIONAL DE IDOSOS
}

\begin{abstract}
Dissertação apresentada como requisito parcial para a obtenção do Título de Mestre em Ciências da Saúde pelo Programa de PósGraduação em Ciências da Saúde da Universidade de Brasília.
\end{abstract}

Aprovado em 25 de novembro de 2016

Prof. Dr. Joaquim Pereira Brasil Neto (presidente)

Universidade de Brasília - UnB

Prof. Dr. Raphael Boechat

Universidade de Brasília- UnB

Prof. Dr. Nasser Allam 
Dedico este trabalho ao meu marido, que sempre me incentivou a continuar, e ao meu fiel companheiro, Apolo, que esperou pacientemente este 


\section{AGRADECIMENTOS}

Ao Professor Dr. Joaquim Brasil Neto, a quem tenho muito respeito e admiração pela dedicação e empenho. Sua paixão pela ciência me incentivou o tempo todo.

Ao Professor Dr. Tomaz, pela atenção e brilhantes ideias. Suas sugestões e críticas fizeram este trabalho florescer.

Ao Professor Danilo Pereira, pelo conhecimento em estatística.

Às Professoras Drª . Corina Satler e Dra . Ana Garcia e Drª Soraya Sá, pela delicadeza e carinho com a neurociência. A busca por resultados e novas pesquisas me encanta em vocês.

À querida xará, Aline lannone, pelo apoio e incentivo. Seu interesse pelo conhecimento aplicado à psicologia é fascinante.

Aos alunos Valentina Moraes, Ester Borigato, Ícaro Rios, Matheus Santos, Rodrigo Melo e Rodrigo Torres, pela disponibilidade em ajudar.

À Karine Alencastro, pela dedicação à língua portuguesa e revisão deste trabalho.

Aos meus pais, por sempre acreditarem em meu potencial.

Muito obrigada a todos! 
"Mudam-se os tempos, mudam-se as vontades, Muda-se o ser, muda-se a confiança; Todo o Mundo é composto de mudança, Tomando sempre novas qualidades..." 


\section{RESUMO}

O transtorno cognitivo leve e as demências têm se tornado problemas médicos cada vez mais frequentes, acompanhando o aumento da longevidade da população. Entretanto, terapias eficazes para essas condições ainda não estão disponíveis. Estudos recentes têm demonstrado que a estimulação transcraniana por corrente contínua (ETCC) é capaz de potencializar o desempenho de indivíduos jovens normais em testes de memória de trabalho. Alterações da memória de trabalho são frequentes em indivíduos idosos, mas poucos estudos têm verificado possíveis efeitos benéficos da ETCC nesse grupo etário. A memória de trabalho envolve diversas estruturas neurais em ambos os hemisférios cerebrais, mas o córtex préfrontal dorsolateral (CPFDL) parece ter um papel fundamental. O presente trabalho teve como objetivo verificar possíveis efeitos da ETCC aplicada sobre o CPFDL esquerdo de indivíduos idosos sobre dois testes de memória operacional: o teste de sequências de letras e números e o teste dos cubos de Corsi (TCC). Dezenove idosos, com idades de 65 a 79 anos, participaram do estudo. Cada voluntário foi submetido a duas sessões de ETCC, uma real e outra fictícia, com a realização dos testes de memória de trabalho durante a estimulação cerebral. A ordem de realização das sessões real e fictícia foi randomizada entre os voluntários, sendo que 10 deles foram submetidos primeiramente à estimulação fictícia. Foi observado um declínio significativo $(p<0,01)$ da performance no TCC durante a estimulação real do CPFDL esquerdo. Também ocorreu piora na execução do teste de sequência de letras e números, porém sem alcançar significância estatística. Este resultado permite concluir que: (1) diferentemente do que foi descrito na literatura para indivíduos jovens, a ETCC anódica do CPFDL esquerdo produz, em idosos, uma 
disrupção dos processos neurais envolvidos na memória de trabalho; (2) o hemisfério cerebral esquerdo também desempenha um papel importante na memória de trabalho visuoespacial, avaliada com o TCC.

Palavras-chave: estimulação transcraniana por corrente contínua; neuromodulação; memória; córtex pré-frontal dorsolateral; idoso. 


\begin{abstract}
Mild cognitive impairment and dementias have become increasingly important medical issues, as populations get older. However, there is still a lack of effective treatments for these conditions. Recent studies have demonstrated that transcranial direct current stimulation (tDCS) is able to enhance the performance of young healthy subjects in tests of working memory. Working memory impairment is frequent in older individuals, but few studies have addressed possible beneficial effects of tDCS in this age group. Working memory engages several structures in both cerebral hemispheres, but the dorsolateral prefrontal cortex (DLPFC) seems to play a fundamental role. This study aimed at verifying possible effects of tDCS applied to the left DLPFC of older subjects upon two working memory tests: letter-number sequencing (LNS) and the Corsi block test (CBT).Nineteen older subjects, aged 65 to 79, took part in the study. Each volunteer underwent two tDCS sessions, one real and the other sham, during the performance of the neuropsychological tests. The order of the real and sham sessions was counterbalanced across subjects, and 10 subjects had the sham session first. There was a significant $(p<0.01)$ decline in performance of the CBT during real anodal tDCS of the left DLPFC. A decline in performance was also present for the LNS, but without statistical significance. These results show that: 1 . in contrast to the improvement reported for young healthy subjects, anodal tDCS of the left DLPFC produces, in older subjects, a disruption of neural processes involved in working memory; 2. the left cerebral hemisphere also seems to play an important role in visuo-spatial working memory, as tested by the CBT.
\end{abstract}


Keywords: Transcranial Direct Current Stimulation; neuromodulation; memory; dorsolateral prefrontal cortex; aged 


\section{LISTA DE ILUSTRAÇÕES}

Figura 1 Múltiplos componentes da memória de trabalho. A área roxa escura representa a memória de longo prazo. Fonte: Baddeley, 2003 (46).

Figura 2 Tipos de correntes elétricas: $(A)$ corrente direta; $(B)$ corrente pulsada monofásica; $(C)$ corrente pulsada bifásica simétrica balanceada; (D) corrente pulsada bifásica simétrica não-balanceada; e (E) corrente pulsada bifásica assimétrica não-balanceada. Fonte: Nelson et al, 2003 (72).

Figura 3 Posicionamento do ânodo em F3 (sistema 10-20). Fonte: Jasper, 1958 (89).

Figura 4 Teste dos Cubos de Corsi visto pelo pesquisador

Figura 5 Teste dos Cubos de Corsi visto pelo participante

Figura 6 Posicionamento dos eletrodos: ânodo na região de $\mathrm{F} 3$, conforme o sistema 10-20 e cátodo no ombro ipsilateral.

Figura 7 Apresentação da pontuação obtida no MoCA

Figura 8 Relação diretamente proporcional entre a pontuação alcançada no MoCA e a idade dos participantes

Figura 9 Variação percentual dos escores do TCC sob estimulação real do CPFDL esquerdo em função do índice do MOCA de cada sujeito. Não há correlação significativa entre essas variáveis $\left(r^{2}\right.$ de Pearson $\left.=-0,05\right)$.

Figura 10 Variação média dos escores no Teste de Sequência de Letras e Números e no Teste dos Cubos de Corsi durante a estimulação real em comparação com a fictícia ("Sham"). Para cada sujeito, o escore obtido durante a estimulação "Sham" foi considerado igual a 1,0. As barras de erro indicam o erro-padrão das médias. (A) Sham, sequência de letras 
e números; (B) Real, sequência de letras e números; (C) Sham, Cubos de Corsi; (D) Real, Cubos de Corsi. * $p<0,01$

Figura 11 Médias dos escores no Teste dos Cubos de Corsi sob estimulação fictícia e sob ETCC real do córtex pré-frontal dorsolateral esquerdo. Observa-se uma queda significativa da performance dos voluntários sob estimulação real $(p<0,01)$. As barras de erro representam o erropadrão da média.

Figura 12 Múltiplas regiões frontais ativadas por tarefas cognitivas bastante diferentes, relacionadas à discriminação auditiva (pontos verdes); à atenção visual dividida (pontos azuis); à modificação de tarefas (pontos alaranjados); solução de problemas espaciais (pontos rosas); e ao processamento semântico de palavras (pontos vermelhos). Fonte: Duncan e Owen, 2000 (118). 


\section{LISTA DE TABELAS}

Tabela 1 - Desempenho nos testes durante a estimulação transcraniana por corrente contínua anódica. 


\section{LISTA DE ABREVIATURAS E SIGLAS}

$\begin{array}{ll}\text { CCL } & \text { Comprometimento Cognitivo Leve } \\ \text { DA } & \text { Doença de Alzheimer } \\ \text { EMT } & \text { Estimulação Magnética Transcraniana } \\ \text { ETCC } & \text { Estimulação Transcraniana por Corrente Contínua } \\ \text { mA } & \text { miliampères } \\ \text { AVC } & \text { Acidente Vascular Encefálico } \\ \text { CPFDL } & \text { Córtex pré-frontal dorsolateral } \\ \text { CPFDLe } & \text { Córtex pré-frontal dorsolateral esquerdo } \\ \text { M1 } & \text { Córtex motor } \\ \text { HERA } & \text { Hemispherical Encoding Retrieval Asymmetry } \\ \text { HAROLD } & \text { Hemispheric Asymmetry Reduction in OLDer adults } \\ \text { mV } & \text { Milivolts } \\ \text { Na+ } & \text { Sódio } \\ \text { K+ } & \text { Potássio } \\ \text { ms } & \text { Milisegundos } \\ \text { AMP-cíclico } & \text { Adenosina Monofosfato Cíclico } \\ \text { Ca++ } & \text { Cálcio } \\ \text { CC } & \text { Corrente Contínua } \\ \text { EEG } & \text { eletroencefalografia } \\ \text { V } & \text { Volts } \\ \text { CEP/FS } & \text { Comitê de Ética em Pesquisa da Faculdade de Ciências da } \\ \text { TCLE } & \text { Saúde da Universidade de Brasília } \\ \text { MoCA } & \text { Termo de Consentimento Livre e Esclarecido } \\ & \text { Montreal CognitiveAssessement (Avaliação Cognitiva de } \\ \text { IDB } & \text { Montreal) } \\ \text { WAIS-III } & \text { Inventário de Depressão de Beck } \\ \text { TCC } & \text { Teste dos Cubos de Corsi } \\ \text { EMTr } & \text { Estimulação Magnética Transcraniana repetitiva } \\ & \end{array}$




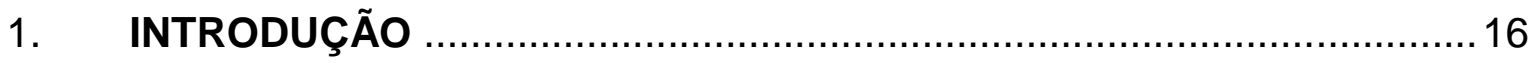

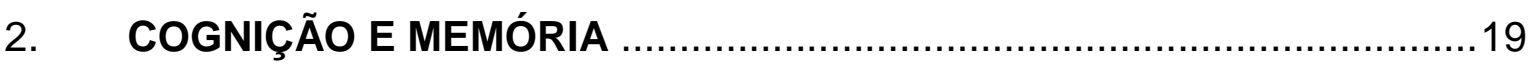

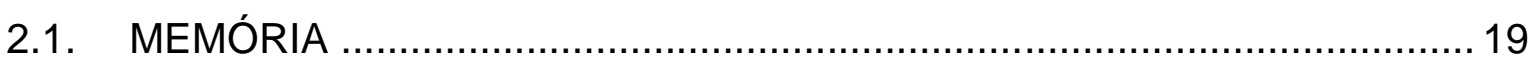

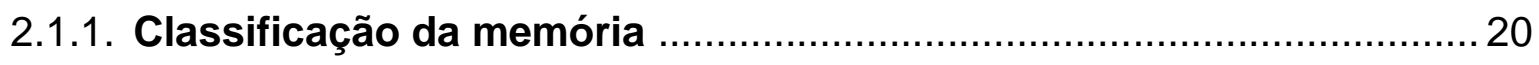

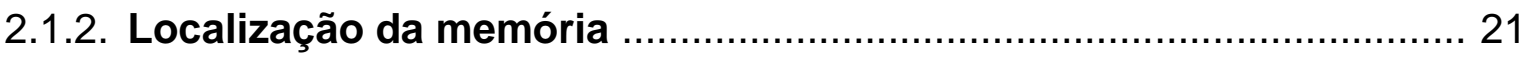

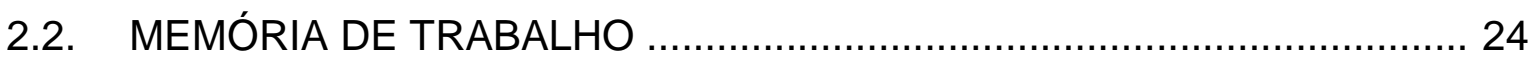

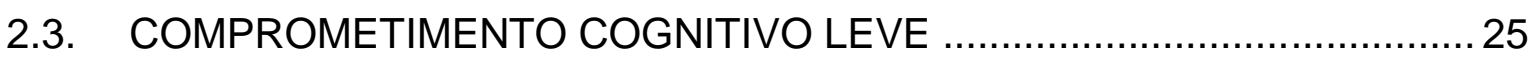

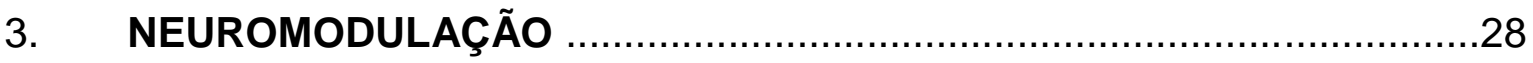

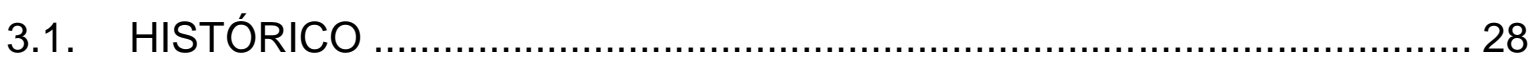

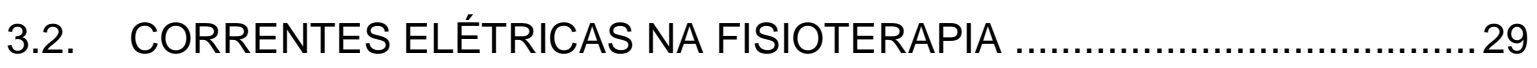

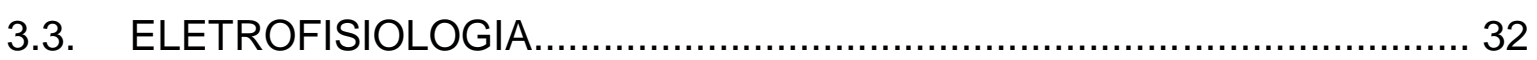

3.4. ESTIMULAÇÃO TRANSCRANIANA POR CORRENTE CONTÍNUA ....... 35

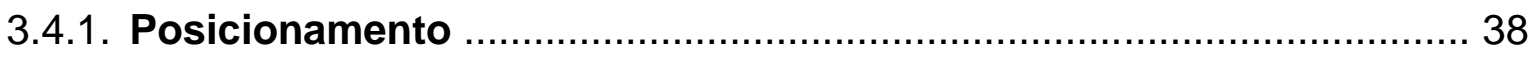

3.4.2. Segurança na aplicação da eletroestimulação .................................... 40

3.4.3. Neuromodulação na memória e cognição ....................................... 40

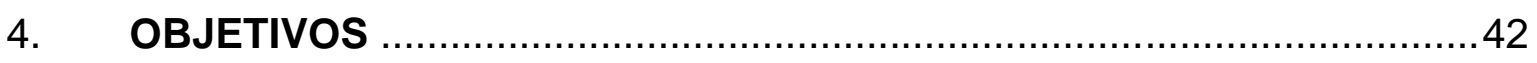

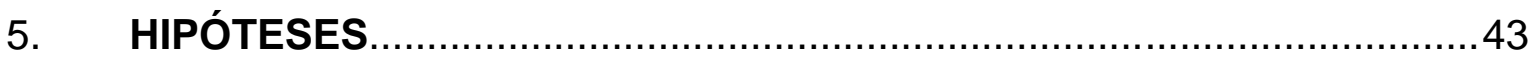

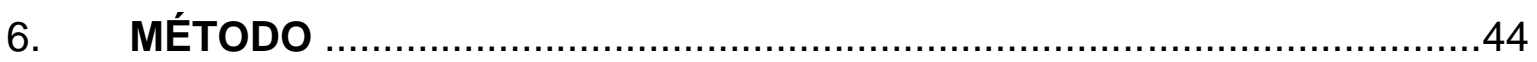

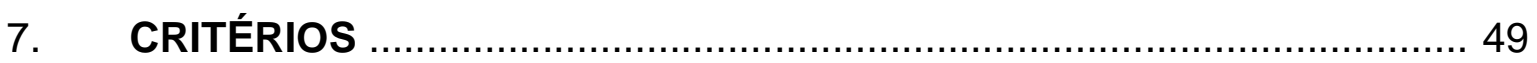

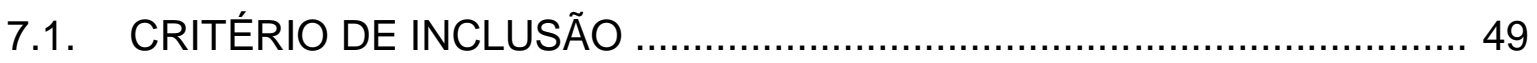

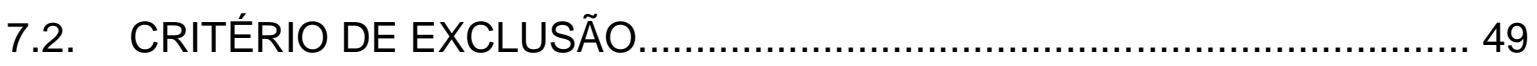

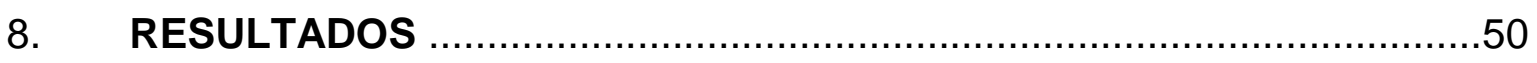

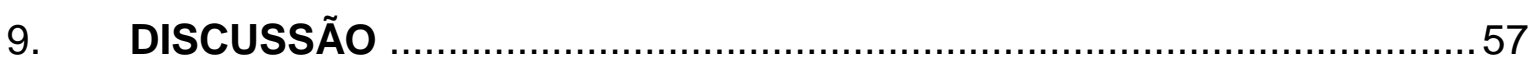

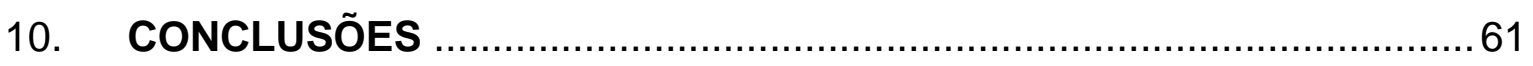

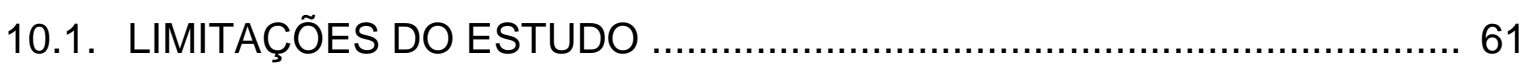

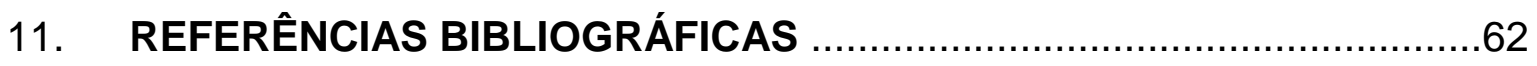

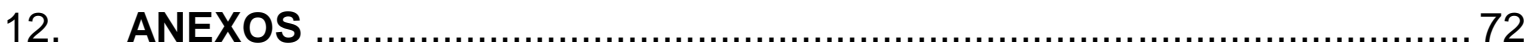




\section{INTRODUÇÃO}

Atualmente, a população com mais de 60 anos aproxima-se de 900 milhões de pessoas, entretanto, embora a expectativa de vida da população mundial esteja crescendo rapidamente, ela está associada à prevalência aumentada de doenças crônicas. O número de casos de pessoas com demência em 2015(1) foi de 46,8 milhões, ao passo que, em 2012, o número era de 36 milhões (2). Estima-se que a prevalência de demência chegará a 74,7 milhões em 2030 e 131,5 milhões em 2050. Estas novas estimativas estão $12-13 \%$ mais altas do que os números apresentados no World Alzheimer Report de 2009 (1).

O comprometimento das habilidades dos pacientes com a doença de Alzheimer resulta em sobrecarga aos pacientes, familiares e à saúde pública. Esses indivíduos geram custos indiretos e diretos. Os indiretos são a perda ou a redução dos ganhos financeiros pelo paciente ou membros da família e têm maior importância para os familiares e a comunidade, já os custos diretos, constituem o tratamento médico e o serviço social, que aumentam com o avançar da doença quando o paciente necessita de um cuidador ou é institucionalizado (3). O impacto econômico da doença, consequentemente, é alto, tendo, em 2010, um custo global de 604 bilhões de dólares e, atualmente, 818 bilhões de dólares, o que corresponde a mais de $1 \%$ do PIB global $(1 ; 2)$.

Independentemente da etiologia, todas as demências, incluindo o comprometimento cognitivo leve (CCL), afetam progressivamente as habilidades cognitivas, comportamentais e funcionais. A limitação das atividades de vida diária compromete as habilidades funcionais e aumenta o risco de mortalidade (4).

O comprometimento cognitivo leve representa o período de transição entre o envelhecimento humano normal e o precoce diagnóstico de provável doença de Alzheimer (DA) (5). O diagnóstico de CCL pode ser realizado por meio do histórico do indivíduo e do exame do estado mental, e complementado com testes neuropsicológicos (6).

Várias tentativas foram realizadas para o desenvolvimento de um tratamento farmacológico com o intuito de melhorar os sintomas ou diminuir a progressão da 
doença de Alzheimer, contudo, até agora, nenhuma droga alcançou essa meta (7). Recentemente, um tratamento não-farmacológico, a Estimulação Magnética Transcraniana (EMT) repetitiva, foi utilizado para melhorar a memória tanto em voluntários saudáveis quanto em pacientes idosos com CCL (8). Bons resultados também foram encontrados com relação à memória e à linguagem em pacientes com DA leve, quando há a administração da EMT em conjunto com treinamento cognitivo (9).

A EMT é capaz de induzir correntes elétricas no parênquima cerebral, de acordo a Lei de Faraday (10). Há décadas são estudados os efeitos das correntes elétricas nas funções neuronais (11). Recentemente, após inúmeros estudos comprovando os efeitos benéficos da EMT sobre desordens neuropsiquiátricas, como a depressão $(12 ; 13)$ e a dor crônica $(14 ; 15)$ e, também, a sua capacidade de modular a função cortical de modo não invasivo, outra técnica de neuromodulação, a Estimulação Transcraniana por Corrente Contínua (ETCC) tem sido foco de diversos estudos (5-24). Existe um grande interesse em suas potenciais aplicações nos campos da neurologia e da psiquiatria (16). A ETCC utiliza corrente elétrica contínua de muito baixa intensidade (1 a 2 miliampères $(\mathrm{mA})$ ), aplicada através do crânio intacto, de forma totalmente não-invasiva e indolor, que parece ser capaz de alterar a excitabilidade neural conforme a polaridade da estimulação. A polaridade da estimulação é capaz de modificar atividade neuronal. A estimulação anódica aumenta a excitabilidade cortical, enquanto a estimulação catódica diminui a excitabilidade do córtex cerebral subjacente $(17 ; 18)$. A técnica de ETCC não é nova (11), mas o interesse nela foi recentemente renovado depois de décadas de esquecimento, possivelmente devido a novas descobertas no campo da neurociência, incluindo o desenvolvimento da EMT que também produz pequenas correntes elétricas intra-corticais (10).

Estudos estão em andamento para explorar possíveis aplicações da ETCC no tratamento de distúrbios neuropsiquiátricos (5-24); em um desses ensaios clínicos, a ETCC anódica foi aplicada na afasia pós-acidente vascular encefálico (AVC) com bons resultados (19). Em pacientes com DA, a estimulação anódica resultou na melhora da memória declarativa (18). Em outro estudo, houve avanço na memória de reconhecimento (20). Em pessoas com CCL, a memória verbal episódica foi 
melhorada (21). O estímulo inibitório (catódico) também foi utilizado em pacientes esquizofrênicos que relatavam alucinações, com resultados satisfatórios (22).

A estimulação pela ETCC provoca mudanças na excitabilidade cortical e possui efeitos terapêuticos (23-28). Em ratos, a estimulação catódica produziu níveis estatisticamente significantes de dopamina extracelular, enquanto que a estimulação anódica não alterou os níveis séricos de serotonina (29), mostrando que ainda há muito a se estudar sobre os potenciais efeitos terapêuticos da ETCC.

Especialmente dignos de nota, no entanto, são os resultados obtidos em indivíduos normais: a ETCC aplicada sobre áreas corticais específicas foi capaz de influenciar beneficamente a memória e a aprendizagem. Os efeitos não se fazem apenas presentes durante o período de estimulação, mas, geralmente, persistem durante horas e até dias após a sessão de estimulação (30). Além disso, verificou-se que o benefício de repetidas sessões de ETCC pode se estender a semanas, ou mesmo meses, em vários distúrbios neuropsiquiátricos (16).

Embora ambos, EMT e ETCC, sejam tratamentos não-farmacológicos para muitas doenças neuropsiquiátricas, a ETCC é especialmente interessante devido à sua simplicidade, baixo custo, segurança e portabilidade. Assim, tendo em vista a recente demonstração de efeitos benéficos da EMT em pacientes com CCL (8), é interessante verificar se a ETCC é capaz de produzir resultados semelhantes mesmo em idosos normais ou com queixas de alterações de memória, que não preencham critérios para um diagnóstico de CCL. 


\section{COGNIÇÃO E MEMÓRIA}

\subsection{MEMÓRIA}

A memória é a habilidade de se lembrar de experiências passadas em nível consciente ou inconsciente (31). É, também, a ferramenta principal do aprendizado, sem a qual, erros seriam cometidos constantemente e os acertos seriam esporádicos. O aprendizado é a capacidade de adquirir novas habilidades e conhecimentos, ao passo que a memória realiza a retenção ou fixação do aprendizado (32). Habituação e sensibilização são formas de aprendizado envolvendo memória que ocorre em nível de sinapse (31). O processo de transformação de uma experiência ou fato em aprendizado concreto produz alterações funcionais persistentes no encéfalo relacionadas a essa experiência. Esse processo é chamado plasticidade do sistema nervoso, e está ligado à capacidade de mudanças do comportamento em resposta aos estímulos dos ambientes externos e internos. A plasticidade envolve alterações como síntese de diferentes proteínas ou brotamento de novos dendritos e alterações na força de conexões sinápticas entre os neurônios (32).

Várias áreas do encéfalo estão envolvidas no processo de aprendizagem e memória, como as áreas associativas dos lobos frontais, parietais, occipitais e temporais, diencéfalo e partes do sistema límbico, tais como hipocampo e a amígdala. Áreas primárias somatossensoriais e motoras também apresentam plasticidade. As representações corporais nas áreas corticais de partes do corpo que são usadas com maior frequência, como na leitura em Braille, se expandem gradualmente, conforme o aprendizado é concretizado (32). 


\subsubsection{Classificação da memória}

A memória pode ser classificada em recente e remota. A recente mantém as informações por dias ou horas e está associada ao sistema límbico, que retém, armazena temporariamente e consolida as informações novas e as transfere para as áreas neocorticais de associação para o armazenamento permanente $(31 ; 32)$.

A memória remota, ou permanente, é estável e armazena dados por anos. As áreas de associação do neocórtex são possivelmente os locais de retenção dos dados, pois não se sabe exatamente onde são armazenadas estas recordações (33).

A memória recente pode ser atingida em diversas situações patológicas, ao passo que a memória remota pode manter-se inalterada mesmo após graves danos cerebrais (31 e 33$)$.

Três mecanismos podem interagir na produção da memória. O primeiro propicia a recordação imediata de fatos; o segundo, os acontecimentos de segundos, horas ou até dias e é responsável pela "consolidação do traço de memória", processo que codifica a memória em uma forma consistente, e o terceiro, veicula memórias do passado remoto (31). Há ainda uma subclassificação, chamada memória imediata, em que as informações duram apenas alguns segundos (33).

O esquecimento de fatos ocorridos antes de alterações cerebrais, como a concussão cerebral ou terapia de eletroconvulsoterapia, é conhecido como amnésia retrógrada. Em seres humanos, o período de amnésia é mais longo do que em animais e, apesar de durar, muitas vezes, dias, semanas e até mesmo anos, a partir de certo ponto do passado, a memória remota permanece prioritariamente preservada. (31 e 34). Já as habilidades motoras podem ser aprendidas normalmente, pois seus mecanismos dependem também do cerebelo (34).

Em animais, a amnésia retrógrada foi comprovada com anestesia, eletrochoque ou hipotermia após cinco minutos de cada sessão de adestramento. Porém, se estas intervenções forem realizadas após quatro horas da sessão de adestramento, os ensinamentos permanecem aprendidos. Ou seja, há um período de "codificação" ou "consolidação" da memória em que o traço da memória é 
vulnerável, contudo, assim como nos seres humanos, este período cessa, permitindo o armazenamento (31).

\subsubsection{Localização da memória}

A localização exata dos processos da memória não se pode afirmar ao certo, porém, sabe-se que há participação do sistema límbico no processo de armazenamento de novas informações (33). A estimulação de partes do lobo temporal em seres humanos consegue evocar detalhes de eventos ocorridos no passado remoto que vão além da recordação voluntária (31). Já o córtex pré-frontal é responsável pela infraestrutura neural para a expressão de emoções, instinto, recompensa e motivação e há forte relação com o sistema límbico, o hipotálamo e o sistema nervoso autônomo (35).

A lesão do corpo amigdaloide interfere nos mecanismos relacionados à memória. Quando experimentado em macacos, a destruição do hipocampo causa um quadro moderado de amnésia e, quando associada à lesão do corpo amigdaloide, torna-se um quadro grave (34).

Conexões do hipocampo ao diencéfalo estão envolvidas na memória. Alguns alcoólatras com lesões cerebrais desenvolvem prejuízo da memória anterógrada e recente, e observa-se a presença de alterações patológicas nos corpos mamilares, que possuem numerosas conexões aferentes e eferentes ao hipocampo via fórnix. Eles podem desenvolver a chamada Síndrome de Korsakoff, que se caracteriza pela amnésia anterógrada em que os sintomas se iniciam com a degeneração dos corpos mamilares em decorrência de alcoolismo crônico (34;36). Em animais de experimentação, a perda de memória recente é causada por lesão no tálamo medial. Além disso, é possível observar nos exames de imagem dos portadores deste problema que os ventrículos laterais e o terceiro ventrículo são dilatados e há alargamento da fissura inter-hemisférica entre os lobos frontais (37). Processos patológicos que acometem o sistema límbico, não apenas os componentes 
temporais, como também o fórnix e corpo mamilar, geram síndromes amnésicas semelhantes a Korsakoff (34). Ou seja, a perda da memória pode ser causada por diversos caminhos.

O processo de codificação da memória ocorre principalmente no hipocampo e suas conexões. A destruição bilateral do hipocampo ventral causa alteração na memória recente, mas mantém inalterada a memória remota e a lembrança imediata. Indivíduos que sofrem com essa destruição, são capazes de aprender, porém devem se manter concentrados na nova tarefa. Caso se distraiam no processo de aprendizagem, toda a memória do que estavam fazendo ou se propondo a fazer, é perdida, mesmo que a distração seja por pouco tempo. Eles mantêm as memórias precedentes à lesão e são capazes de novos aprendizados, mas não podem formar novas memórias em longo prazo (31).

A remoção terapêutica bilateral de parte do lobo temporal, contendo o hipocampo, em pacientes com epilepsia grave levou-os a um quadro de amnésia anterógrada, ou seja, os pacientes perderam a capacidade de guardar informações novas após o ato cirúrgico (34).

Suspeita-se que na doença de Alzheimer dois fatores principais levam à amnésia total e perda das funções cognitivas. Um deles é a degeneração dos neurônios colinérgicos do núcleo basal de Meynert, levando à alteração na função moduladora sobre a atividade dos neurônios do sistema límbico e do neocórtex relacionado com a memória. O segundo fator e, provavelmente, o principal, é a degeneração seletiva de dois grupos de neurônios do sistema límbico. O primeiro está localizado no hipocampo, nas áreas que dão origem às principais fibras eferentes, e o segundo está na área entorrinal, no giro para-hipocampal, onde as vias do neocórtex chegam, se dirigem a esse giro e seguem em direção ao hipocampo (34). Lesões gradativas, como na DA, isolam o hipocampo e apresentam consequências à memória equivalentes aos casos de ablação do hipocampo, como descrito acima.

Sabe-se que há participação do sistema límbico, em especial do hipocampo e da amígdala, no processo de consolidação da memória recente e sua transformação em memória remota, porém, não se sabe ao certo de que forma isto ocorre. Uma das hipóteses é de que a memória recente seja armazenada temporariamente no hipocampo e na amígdala e transferida para o neocórtex para armazenamento 
permanente. Outra hipótese é que a memória recente já estaria no neocórtex desde o início, e gradualmente seria consolidada e transformada em memória remota por ação do hipocampo e da amígdala, agindo através de suas conexões com o neocórtex (34).

A parte anterior não motora do lobo frontal é a área pré-frontal, caracterizada como córtex de associação supramodal. Esta área participa do controle do comportamento emocional e memória (34). Ela representa um quarto da superfície do córtex cerebral e desenvolveu-se durante a evolução dos mamíferos (33). Ligando-se ao sistema límbico, ela recebe fibras de todas as demais áreas de associação através dos fascículos de associação do córtex. Especialmente importantes são as extensas conexões recíprocas que ela mantém com o núcleo dorsomedial do tálamo.

Experiências com macacos e a observação de casos clínicos possibilitou a compreensão do significado funcional da área pré-frontal. Fulton e Jacobsen, em 1935, removeram a área pré-frontal de duas chimpanzés em um estudo e elas começaram a esquecer onde haviam escondido o alimento em pouco tempo, sugerindo que há uma ligação entre a memória recente e a área pré-frontal. As macacas também não apresentaram manifestações emocionais de descontentamento, como frustração e tornaram-se distraídas (34 e 38).

Interessantemente, a sensação de dejá vu (palavra francesa que significa já visto) é um sentimento inapropriado de familiaridade em novos ambientes ou com novos acontecimentos. É comum ocorrer em indivíduos normais, mas também pode ser um sintoma de aura (sensação que precede imediatamente a crise) em pacientes com epilepsia do lobo temporal (31).

Não há dúvidas sobre o papel do córtex pré-frontal dorsolateral (CPFDL) na memória episódica, mas estudos de neuroimagem têm mostrado que há uma rede neural envolvida no processo de memorização e é constituída não apenas do CPFDL, mas, também, dos lobos temporais mediais, do córtex parietal e dos córtices pré-occiptais (39-45). 


\subsection{MEMÓRIA DE TRABALHO}

A memória de trabalho, assim como outras funções executivas, faz parte das responsabilidades do córtex pré-frontal. Basicamente, o córtex pré-frontal tem três funções: (1) atenção executiva, memória de trabalho e controle inibitório; (2) o planejamento; e (3) a tomada de decisões. O córtex pré-frontal dorsolateral é a base neural para aspectos cognitivos da organização temporal e do controle cognitivo (35).

Segundo Baddeley (2003) (46), "o conceito de memória de trabalho propõe que um sistema dedicado mantém e armazena informação em curto prazo, e que esse sistema é a base dos processos do pensamento humano. A visão atual da memória de trabalho envolve um executivo central e dois sistemas de armazenamento: a alça fonológica e o esboço visuoespacial."

Estudos baseados na localização de lesão em pacientes, bem como estudos de neuroimagem indicam que os três componentes básicos da memória de trabalho estão localizados em diferentes regiões cerebrais. A alça fonológica foi relacionada, por esses estudos, com a região temporoparietal esquerda, e a memória de trabalho visuoespacial parece estar localizada principalmente no hemisfério cerebral direito. O executivo central teria representação bilateral nas regiões pré-frontais (Baddeley, 2003) (46) (figura 1) 


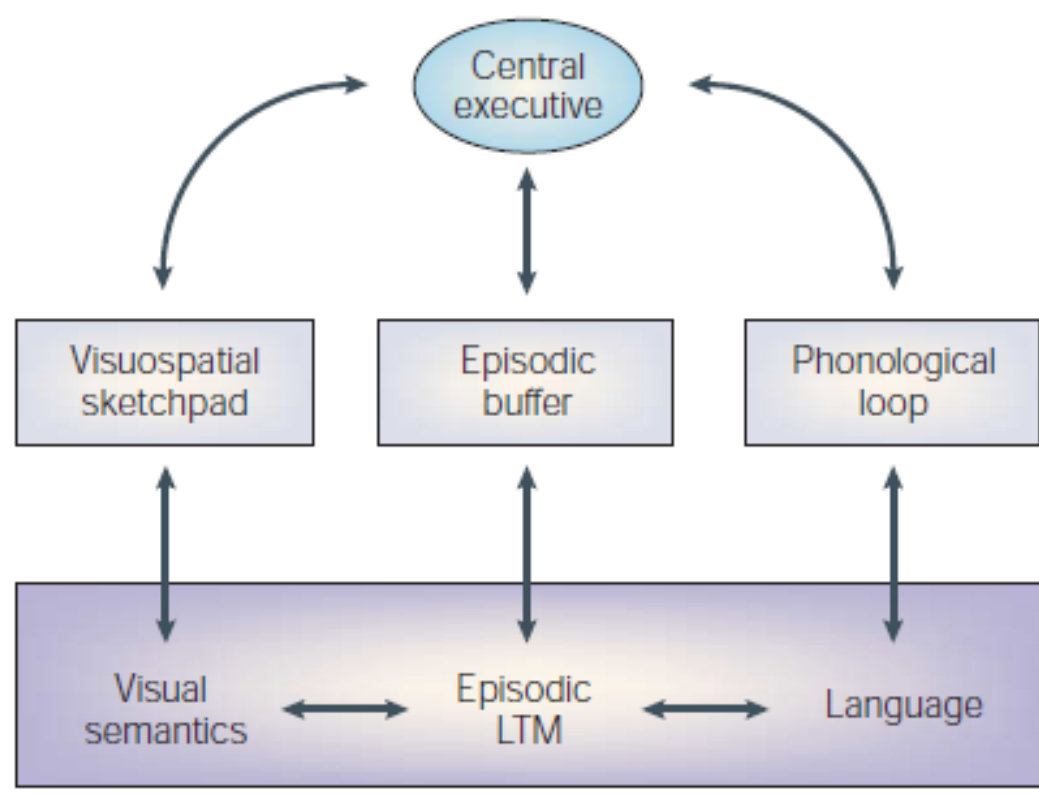

Fluid systems

Crystallized systems

Figura 1 Múltiplos componentes da memória de trabalho. A área roxa escura representa a memória de longo prazo. Fonte: Baddeley, 2003 (46).

Para testar o efeito da ETCC na memória de trabalho um estudo utilizou a corrente anódica no córtex pré-frontal dorso lateral esquerdo (CPFDLe) e testou o mesmo efeito com a corrente catódica no CPFDLe e anódica na região do córtex motor (M1). O estudo constatou que apenas a estimulação anódica foi significativamente facilitadora da memória de trabalho (26).

\subsection{COMPROMETIMENTO COGNITIVO LEVE}

O envelhecimento natural do ser humano é capaz de provocar alterações nos mecanismos neurais relativos ao declínio da memória (47-54). Adultos jovens apresentam um padrão assimétrico de codificação e recuperação, conforme a teoria da Assimetria de Codificação da Evocação Hemisférica, conhecida como HERA (do 
inglês Hemispherical Encoding Retrieval Asymmetry) (55), em que o córtex préfrontal esquerdo é especializado em codificação, enquanto o direito é especializado em recuperação, porém os adultos mais velhos apresentam uma redução deste padrão, conhecido como padrão HAROLD (do inglês Hemispheric Asymmetry Reduction in OLDer adults) (56).

As características clínicas da transição entre o envelhecimento cognitivo normal e a demência são diagnosticadas como comprometimento cognitivo leve (CCL) (4).

O CCL está associado à queixa de incapacidades funcionais, como nas atividades de vida diária e nas atividades instrumentais (5). Porém, pacientes com CCL comumente apresentam patologias concomitantes que levam a incapacidades físicas. Portanto, determinar o limite entre a contribuição mental e física para a incapacidade, torna-se difícil. $(4 ; 57)$.

Em 1997, Petersen et al (58) criaram critérios para o conceito de comprometimento cognitivo leve que incluíam (1) problemas de memória, (2) distúrbio de memória objetiva, (3) ausência de distúrbios cognitivos ou repercussões na vida diária, (4) função cognitiva geral normal e (5) ausência de demência. Com o avançar dos estudos, em 2004 (59), este conceito adquiriu classificações pelo Grupo Internacional de Estudos do Comprometimento Cognitivo Leve em que há subdivisões de CCL, baseadas na avaliação da memória e de outros domínios cognitivos, como a linguagem, funções executivas, atenção e habilidades visuoespaciais.

OCCL pode ser dividido em subtipos amnésicos e não-amnésicos (7). $\mathrm{O}$ primeiro tipo de CCL é o amnésico que pode ser de um domínio ou de múltiplos domínios. Neste último caso, há comprometimento não apenas da memória, mas das outras funções. Esse tipo tende a evoluir para a doença de Alzheimer $(7 ; 59)$.

O segundo tipo de CCL é o não-amnésico, no qual há prejuízo de algum domínio diferente da memória (único domínio), que pode chegar à doença de Alzheimer ou CCL não-amnésico de múltiplos domínios. O CCL não-amnésico de múltiplos domínios, pode evoluir tanto para a DA quanto para outros tipos de demência, porém, pode, também, apresentar um processo de envelhecimento considerado normal (59). 
A progressão do $C C L$ pode, em muitos casos, levar ao estágio inicial da doença de Alzheimer; entretanto, outros tipos de demências podem ser desencadeados, como a demência vascular, demência dos corpúsculos de Lewi ou atrofia cerebral (59).

Gradativamente, a DA afeta a memória recente, porém em fases avançadas da doença pode haver amnésia total e deterioração das funções cognitivas (34).

O diagnóstico do comprometimento cognitivo leve permite intervenções no início do declínio cognitivo, antes que o indivíduo desenvolva algum tipo de demência, como o provável diagnóstico de doença de Alzheimer. Com o diagnóstico de CCL, as possibilidades de intervenção terapêutica aumentam e a chance de atrasar o desenvolvimento de patologias cognitivas mais graves é proporcional a esse aumento $(7 ; 60)$.

Uma revisão em 2014 (61) sugere que há neurodegenerações precoces comuns em imagens de ressonância magnética de indivíduos com doença de Huntington e nas imagens de indivíduos com comprometimento cognitivo leve amnésico.

Assim como pode ocorrer neurodegenerações precoces, outros estudos sugerem que há hiperatividade neuronal em idosos comparado às atividades neuronais dos jovens $(62 ; 63)$. 


\section{NEUROMODULAÇÃO}

\subsection{HISTÓRICO}

O uso de corrente elétrica para tratamento de enfermidades foi registrado pela primeira vez entre 43 e 48 depois de Cristo. Médicos colocavam peixes elétricos enrolados na cabeça de pacientes com queixa de cefaleia e estes desencadeavam um efeito entorpecente, aliviando imediatamente a dor de cabeça (11).

A história da estimulação do cérebro humano por corrente elétrica é antiga. No século XIX, os primeiros relatos descrevem a aplicação de corrente elétrica em um ponto isolado de um cérebro exposto, o que torna a estimulação cerebral um grande avanço na neurociência $(64 ; 65)$.

A primeira estimulação cerebral relatada foi feita na Itália (66). Em 1802, Giovanni Aldini, renomado professor de física da Universidade de Bolonha, usou corrente elétrica para estimular as meninges e a superfície cortical de dois prisioneiros decapitados (67). Aldini percebeu que, com a estimulação elétrica no córtex esquerdo, houve uma contração na hemiface direita, então ele concluiu que era possível excitar eletricamente a superfície cortical. Embora, as contrações musculares possam ter sido reflexo da ativação direta do nervo facial, este autor merece reconhecimento por ter publicado o primeiro relato de estimulação elétrica no córtex humano (64). Aldini inovou também com o uso transcraniano da corrente galvânica em pacientes melancólicos (67).

Apenas na década de 1870 , os achados de Aldini foram valorizados e novos estudos surgiram. Três grupos independentes de cientistas iniciaram seus estudos com diferença de poucos anos: Bartholow, nos Estados Unidos, em 1874; Sciamanna, na Itália, em 1882; e, Alberti, na Argentina, em 1884. Eles decidiram replicar os estudos de Fritsch e Hitzig de 1870, que tiveram como objetivo determinar se as respostas motoras encontradas eram de origem central, estudando os efeitos da corrente galvânica sobre diferentes áreas do córtex cerebral de um cachorro consciente. Ferrier em 1873, também pesquisou o uso da corrente em animais (64). 
Apesar da técnica de ETCC não ser nova (11), o interesse nela foi recentemente renovado, depois de décadas de esquecimento, possivelmente, devido a novas descobertas no campo da neurociência, incluindo o desenvolvimento da EMT, que também produz pequenas correntes elétricas intracorticais (10).

Os estudos sobre a estimulação elétrica transcraniana com corrente contínua iniciaram-se na década de 1960 com experimentação animal (68; 69). Em 1964, Bindman e colaboradores (68) publicaram um estudo mostrando que potenciais de membrana em repouso poderiam ser ativados com a aplicação de correntes de baixa intensidade sobre as áreas corticais de ratos e que este efeito poderia durar por horas após o término da estimulação. Purpura e McMurtry, em 1965, (69) puderam observar o aumento da excitabilidade neuronal espontânea após a aplicação da ETCC anódica em células do trato piramidal de gatos e o inverso com a estimulação catódica. A partir dessa década, o objetivo das aplicações foi melhorar as funções do cérebro envolvidos no processo de aprendizagem e memória e ajudar nas alterações patológicas das doenças neuropsiquiátricas. Mas o interesse terapêutico da ETCC foi diminuído devido a limitações tecnológicas da época e ao incremento da indústria farmacêutica. (11)

O interesse pela aplicação transcraniana da corrente galvânica de baixa intensidade ressurge na década de 1990, com protocolos estruturados. Em 1998, Priori e colaboradores (70) comprovaram, através da estimulação magnética transcraniana (EMT), que durante a ETCC catódica de baixa intensidade $(>0,5 \mathrm{~mA})$ a excitabilidade do córtex motor (M1) em humanos diminuiu. Nitsche e Paulus (23), em 2000, realizaram um estudo semelhante, com baixa intensidade, comprovando, através da EMT, que o efeito polaridade dependente da ETCC se mantém após a estimulação do córtex motor de indivíduos saudáveis (71).

\subsection{CORRENTES ELÉTRICAS NA FISIOTERAPIA}

As correntes elétricas terapêuticas são classificadas em dois tipos: corrente contínua (ou corrente direta) e corrente alternada (figura 2). A corrente contínua mantém o fluxo constante de partículas carregadas em uma única direção, e é dependente da polaridade da força eletromotriz aplicada. Na corrente alternada, o 
fluxo é contínuo, mas bidirecional. A corrente alternada pode ser simétrica, na qual o fluxo de corrente é igual nas duas direções, ou assimétrica, na qual o fluxo é diferente em cada uma das direções (72). Há uma terceira classificação de corrente, a corrente pulsada, chamada também de corrente pulsátil ou corrente interrompida, em que o fluxo não é contínuo. As correntes contínuas ou alternadas podem ser moduladas em correntes pulsadas, caracterizada pela interrupção completa do fluxo (figura 2). 

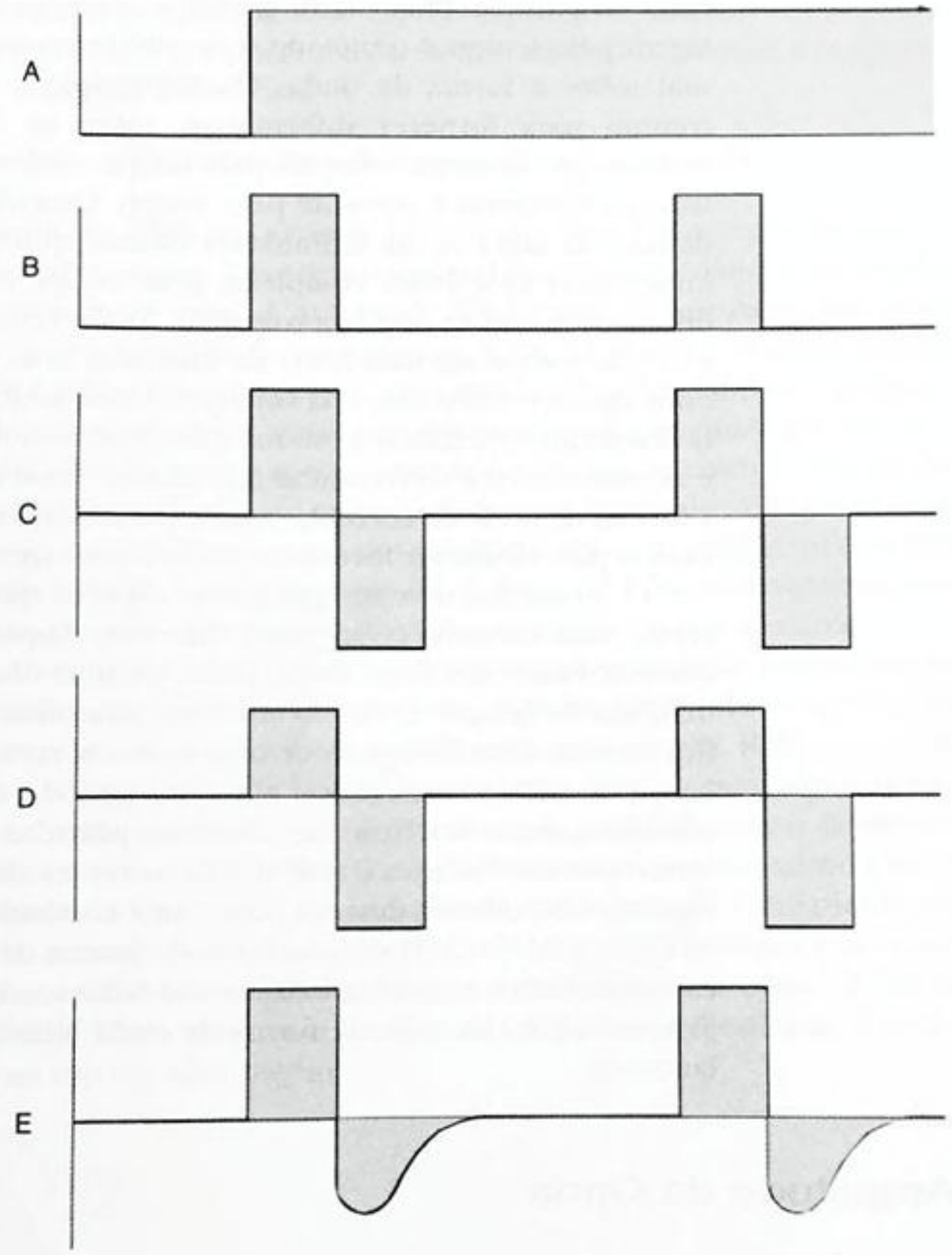

Figura 2 Tipos de correntes elétricas: (A) corrente direta; (B) corrente pulsada monofásica; (C) corrente pulsada bifásica simétrica balanceada; (D) corrente pulsada bifásica simétrica não-balanceada; e (E) corrente pulsada bifásica assimétrica não-balanceada. Fonte: Nelson et al, 2003 (72). 


\subsection{ELETROFISIOLOGIA}

As células excitáveis são protegidas por uma membrana que separa as cargas intracelular e extracelular. A carga sobre a membrana é resultante da diferença nas concentrações de íons em ambos os lados de sua estrutura. Essa carga, ou potencial de repouso da membrana, é mensurada normalmente entre $60 \mathrm{e}$ 90 milivolts $(\mathrm{mV})$, sendo o interior da célula menos positivo do que o meio extracelular. Nas células musculares e neurais normais, a concentração de sódio $(\mathrm{Na}+)$ é maior no exterior da célula, ao passo que a concentração de potássio $(K+)$ é maior no interior (73).

Para equalizar as concentrações, cada íon difunde-se passivamente pela membrana. A capacidade de difusão é determinada pela permeabilidade da membrana àquele íon (73).

A permeabilidade da membrana aos íons $\mathrm{K}+$ é maior do que aos íons $\mathrm{Na}+$, fazendo com que um número maior de cargas positivas $K+$ saia da célula, desenvolvendo um potencial menos positivo no interior dela. Eventualmente, uma força eletrostática opositora faz com que os íons $\mathrm{K}+$ que, naturalmente, pela força de difusão sairiam da célula, ajam no sentido contrário, devido ao potencial negativo intracelular. O potencial de equilíbrio de $\mathrm{K}+(-100 \mathrm{mV})$ ocorre quando essas forças se igualam, tornando a condição estável, ou seja, para cada íon que entra na célula, outro sai (73).

Apesar do potencial de equilíbrio de $\mathrm{K}+$ ser de $-100 \mathrm{mV}$, o potencial de repouso da membrana está entre -60 e $-90 \mathrm{mV}$, pois outros íons estão se movendo passivamente através da membrana, por exemplo o $\mathrm{Na}$. O potencial de repouso de uma membrana excitável é resultado da diferença de concentração e da permeabilidade ao $\mathrm{Na}+$ e ao $\mathrm{K}+$ (73).

As células excitáveis estão constantemente sendo submetidas a eventos que mudam a permeabilidade da membrana aos íons $\mathrm{K}+$ e $\mathrm{Na}+$, ou seja, saindo do potencial de repouso. A membrana celular pode ser excitada por meio de estímulos químicos, elétricos ou físicos, que podem gerar um pequeno aumento da permeabilidade ao $\mathrm{Na}+$. Conforme a quantidade de íons $\mathrm{Na}+$ que entra na célula aumenta, ocorre uma despolarização. Quando esta despolarização alcança um limiar, a permeabilidade da membrana aumenta drasticamente, permitindo a entrada 
brusca de $\mathrm{Na}+$ na célula. Assim, o potencial da membrana muda rapidamente para +25 a +35mV e tem duração de 0,5 milissegundos (ms) (73).

$\mathrm{O}$ aumento da permeabilidade do $\mathrm{K}+$ tem seu pico um pouco mais tarde do que o aumento para os íons $\mathrm{Na}+$, pois este atraso faz com que o potencial de membrana torne-se negativo (hiperpolarização), aproximando-se do potencial de equilíbrio do $K_{+}$. Essa alteração repentina na permeabilidade da membrana é conhecida como potencial de ação. A capacidade de uma membrana em gerar um potencial de ação é a propriedade que define uma membrana excitável (73).

Para restabelecer o equilíbrio basal ou potencial de repouso, uma bomba de $\mathrm{Na}+\mathrm{K}+$ é ativada, retirando o $\mathrm{Na}+$ da célula e introduzindo $\mathrm{K}+$ numa proporção de 3 para 2 (73).

Embora as células excitáveis normais apresentem muito frequentemente potenciais de ação, existem condições que fazem com que a membrana excitável falhe. A membrana pode tornar-se despolarizada, porém, não necessariamente o suficiente para atingir o limiar de disparo, além disso, as células podem apresentar uma acomodação aos estímulos. Outra característica importante é o fato de que nem todas as membranas acomodam-se no mesmo nível. Por exemplo, o sarcolema do músculo tem menor acomodação aos estímulos que o nervo (73).

O caminho percorrido pela corrente elétrica inclui fibras nervosas de diferentes diâmetros. Fibras de maior diâmetro requerem estímulos de amplitude e tempo de duração menores devido às menores resistências. Fibras de menor diâmetro requerem estímulos de maior amplitude e tempo de duração para alcançar o limiar do que as fibras de maior diâmetro. As fibras responsáveis pela sensação de dor cutânea, por exemplo, são normalmente de menor calibre, assim, a estimulação elétrica de baixa amplitude, pequena duração, ou ambos, podem reduzir a sensação de dor que acompanha a estimulação (73).

A estimulação de um nervo periférico com o objetivo de gerar uma contração muscular não despolariza todos os motoneurônios alfa do nervo no mesmo limiar ou amplitude de estímulo. Para recrutar todos os neurônios motores, algumas vezes, é preciso uma amplitude mais alta, inclusive acima da tolerância do paciente (73).

Com relação à memória, a sensibilização de uma resposta que ocorre em invertebrados, como a Aplysia, envolve uma forma de memória. A sensibilização em curto prazo envolve uma ação da adenosina monofosfatocíclico (AMP-cíclico) para 
inativar alguns canais de $\mathrm{K}_{+}$, prolongando assim o potencial de ação e aumentando o cálcio $(\mathrm{CA}++)$ intracelular, de tal forma que mais transmissores sejam liberados. $A$ sensibilização em longo prazo também ocorre na Aplysia. Nesta forma de sensibilização, foi sugerido que a síntese proteica é estimulada e a produção de uma subunidade confere uma maior especificidade para a quinase, e deste modo, um maior efeito sobre os canais de $\mathrm{K}_{+}$, o que, consequentemente, produz maior efeito na concentração de $\mathrm{K}+\mathrm{e}$ por isso o influxo de $\mathrm{Ca}++$ é produzido para uma dada quantidade de AMP-cíclico (31).

Por sua vez, a estimulação anódica por corrente contínua aplicada sobre o córtex sensitivo-motor de ratos é capaz de provocar um acúmulo de adenosina monofosfato cíclico (74), induzindo um aumento na proteína quinase $\mathrm{C}$ e, consequentemente, nos níveis de Cálcio $(75 ; 76)$. Em coelhos, foi possível observar a participação dos receptores A1 de adenosina no aprendizado associativo (77). Outro estudo em ratos mostrou que a estimulação catódica incentiva o aumento dos níveis de dopamina extracelular, e que a estimulação anódica não altera os níveis séricos de serotonina, provando que há efeitos orgânicos com a estimulação (29).

Os efeitos obtidos pela ETCC dependem da polaridade. Enquanto a estimulação catódica resulta em diminuição da excitabilidade cortical, em função de hiperpolarização do neurônio, a estimulação anódica tem efeito inverso. As alterações na função da membrana neuronal promovidas pela ETCC podem ter como base alterações em proteínas transmembranas e mudanças na concentração de hidrogênio com base na eletrólise induzida pela exposição constante ao campo elétrico (79-83).

Um estudo com a espectroscopia por ressonância magnética nuclear evidenciou que a ETCC anódica (excitatória) causa redução local do GABA, enquanto a ETCC catódica (inibitória) causa atividade neuronal glutamatérgica reduzida (84). 


\subsection{ESTIMULAÇÃO TRANSCRANIANA POR CORRENTE CONTÍNUA}

A corrente contínua (CC) ou direta é a corrente elétrica unidirecional que flui em uma única direção por pelo menos um segundo. Historicamente, a corrente contínua é conhecida como corrente galvânica. A corrente que flui unidirecionalmente por menos de 1 segundo é uma corrente pulsada (78).

O fluxo de uma CC pode ser modulado para propósitos clínicos. As três modulações mais comuns são: reversa, interrompida e com rampa. Na corrente contínua reversa, a direção do fluxo da corrente é invertida, a amperagem é negativa, ou seja $-1 \mathrm{~mA}$. A corrente flui na direção correta por pelo menos um segundo e na direção oposta pelo mesmo tempo (78).

A característica da corrente contínua interrompida é o espaçamento de pelo menos um segundo entre os momentos que a corrente passa. A interrupção é normalmente conseguida por meio de um interruptor manual ou automático. A indicação mais comum é na estimulação de músculos denervados durante o eletrodiagnóstico ou em neuromodulação, como a EMT e a ETCC. A última variação da modulação da corrente contínua é uma opção mais confortável para o paciente, no qual o pulso elétrico aumenta gradativamente a amplitude até alcançar a amplitude ideal (78). Desta forma, a ETCC é uma técnica de modulação cortical nãoinvasiva e indolor, que é capaz de elevar a excitabilidade cortical com a estimulação anódica, ao passo que com a estimulação catódica é capaz de diminuir a excitabilidade do córtex cerebral da região subjacente e, assim, interferir em diversas funções cognitivas e motoras a depender da localização do estímulo (15; 16; 24).

Os efeitos da ETCC são alterados conforme a direção e duração do fluxo da corrente elétrica, assim como a intensidade, a polaridade e o posicionamento dos eletrodos $(23 ; 27 ; 85)$.

A posição dos eletrodos na estimulação transcraniana depende da área cortical que deve ser estimulada e se o efeito será excitatório ou inibitório. Geralmente, é utilizado o sistema 10-20 de posicionamento de eletrodos da eletroencefalografia (EEG), pois este sistema é baseado em porcentagem de medida, e assim considera a variação no tamanho dos crânios (86). Os efeitos da ETCC também estão relacionados à densidade de corrente e à carga total aplicadas. 
A densidade de corrente corresponde à relação entre a intensidade da corrente utilizada e a área do eletrodo. Enquanto a carga total equivale à razão entre a intensidade da corrente administrada e o produto entre a área do eletrodo e a duração da estimulação (87).

Alguns estudos avaliaram o efeito da ETCC do córtex pré-frontal dorsolateral esquerdo sobre a memória, geralmente com resultados favoráveis sobre os testes neuropsicológicos utilizados. Entretanto, poucos realizaram os testes de memória "online", ou seja, durante a própria estimulação. Sabe-se que há melhora na memória após a estimulação anódica transcraniana. Por exemplo, Fregni et al (2005) (26) verificaram que a estimulação anódica demonstrou efeitos benéficos sobre a memória de trabalho, quando comparada com a estimulação catódica no CPFDLe em jovens (média de idade 20,2 anos). O eletrodo positivo foi colocado sobre F3 e o negativo na região orbital contralateral. Com relação à localização do estímulo, não foi possível encontrar resultados estatisticamente significativos da estimulação anódica em M1 sobre a memória de trabalho, comparativamente à mesma polaridade aplicada sobre o CPFDLe.

Em outro estudo, Javadi e Walsh (2012) (17) avaliaram os efeitos da ETCC anódica ou catódica aplicada sobre o CPFDL esquerdo (F3 do sistema 10-20) na memória de trabalho em jovens (média de idade 22,46 anos). A estimulação foi realizada nas duas etapas da memória de trabalho (codificação e reconhecimento) em momentos diferentes. Os resultados mostraram que a estimulação anódica do CPFDL esquerdo durante a codificação ("online") melhora a performance na fase de reconhecimento, enquanto a ETCC catódica teve efeito contrário. E, da mesma forma, quando a ETCC foi realizada durante a fase de reconhecimento, a catódica degradou o desempenho comparativamente à estimulação fictícia, enquanto a anódica tendeu a melhorar a performance. Além disso, assim como Fregni et al (2005) (26), Javadi e Walsh (2012) testaram o efeito da ETCC em M1 (C3 do sistema 10-20) e observaram que a estimulação anódica na fase de codificação não alterava o desempenho na etapa de reconhecimento (17).

Além desses estudos com voluntários jovens saudáveis, alguns pesquisadores avaliaram os possíveis efeitos benéficos da ETCC sobre a memória em pacientes portadores de quadros neurológicos. No Egito, por exemplo, Khedr e colaboradores (2014) (88) publicaram um estudo em que 34 pessoas com doença 
de Alzheimer foram submetidas a dez sessões diárias de 25 minutos de ETCC anódica, catódica ou placebo sobre o córtex pré-frontal dorsolateral esquerdo. A estimulação foi de $2 \mathrm{~mA}$ de intensidade. Os sujeitos foram avaliados em quatro quesitos com o Mini Exame do Estado Mental e o WAIS-III: (1) compreensão verbal; (2) memória de trabalho; (3) organização visuoespacial; e (4) velocidade de processamento. Os resultados foram avaliados antes e após as dez sessões, um mês e dois meses após o término das sessões e mostraram que tanto com a estimulação anódica quanto com a catódica, os resultados foram melhores após a ETCC, na comparação com o placebo.

Boggio et al (2009) (20) aplicaram a ETCC anódica em dois diferentes pontos de estimulação, córtex temporal esquerdo e córtex pré-frontal dorsolateral esquerdo, em idosos com doença de Alzheimer, com o objetivo de verificar os efeitos da estimulação na memória de reconhecimento visual, memória de trabalho e atenção seletiva. Adicionalmente, foi realizada estimulação placebo, totalizando três aplicações por 30 minutos cada, em dias diferentes. Os testes utilizados foram: teste de Stroop; teste de evocação de dígitos; e teste de memória de reconhecimento visual. A bateria de testes foi iniciada após dez minutos da estimulação e os efeitos foram avaliados após cada sessão. Os autores puderam observar melhora significativa no teste de memória de reconhecimento visual comparando individualmente os pontos de estimulação com o placebo, porém não houve diferença entre os pontos de aplicação da ETCC.

Assim como nos estudos com ETCC, na estimulação magnética transcraniana aplicada sobre o CPFDL esquerdo, os indivíduos também apresentaram melhora na memória de trabalho, conforme o estudo de Marra e colaboradores (2015) (8) que realizaram um estudo duplo-cego controlado com dez sessões de estimulação magnética transcraniana repetitiva (EMTr) de alta frequência sobre o CPFDL esquerdo em 34 idosos com comprometimento cognitivo leve divididos em dois grupos, sendo 19 indivíduos no grupo controle. Eles observaram melhor desempenho na memória de trabalho. A avaliação neuropsicológica foi repetida após um mês e os resultados se mantiveram. Nesse caso, entretanto, a avaliação dos efeitos da EMT repetitiva não foi realizada "online", ou seja, durante a estimulação. 


\subsubsection{Posicionamento}

O posicionamento dos eletrodos para neuromodulação por ETCC é feito através do sistema internacional 10-20 de colocação de eletrodos para eletroencefalografia, em que o pesquisador mede o crânio paciente de násion ao ínion e de tragus a tragus. A partir destas medidas, é possível determinar o exato ponto de CZ (ponto central), no plano sagital, os pontos de Fpz e Fz e no coronal, T3 e C3, pontos de base para encontrar F3. Partindo da circunferência que passa sobre $\mathrm{Fpz}, \mathrm{T} 3, \mathrm{Oz}$ e T4, encontra-se F7 e então, F3, ponto mediano entre F7 e Fz (figura 3) (89).

O objetivo deste estudo foi estimular a região do córtex pré-frontal dorso lateral esquerdo e, para isso, houve a colocação do eletrodo anódico nas sessões de ETCC na região de F3 conforme o sistema internacional 10-20 (89) e o eletrodo catódico (polo negativo) sobre a região do ombro ipsilateral. Os participantes ficaram sentados confortavelmente e em um ambiente reservado. 


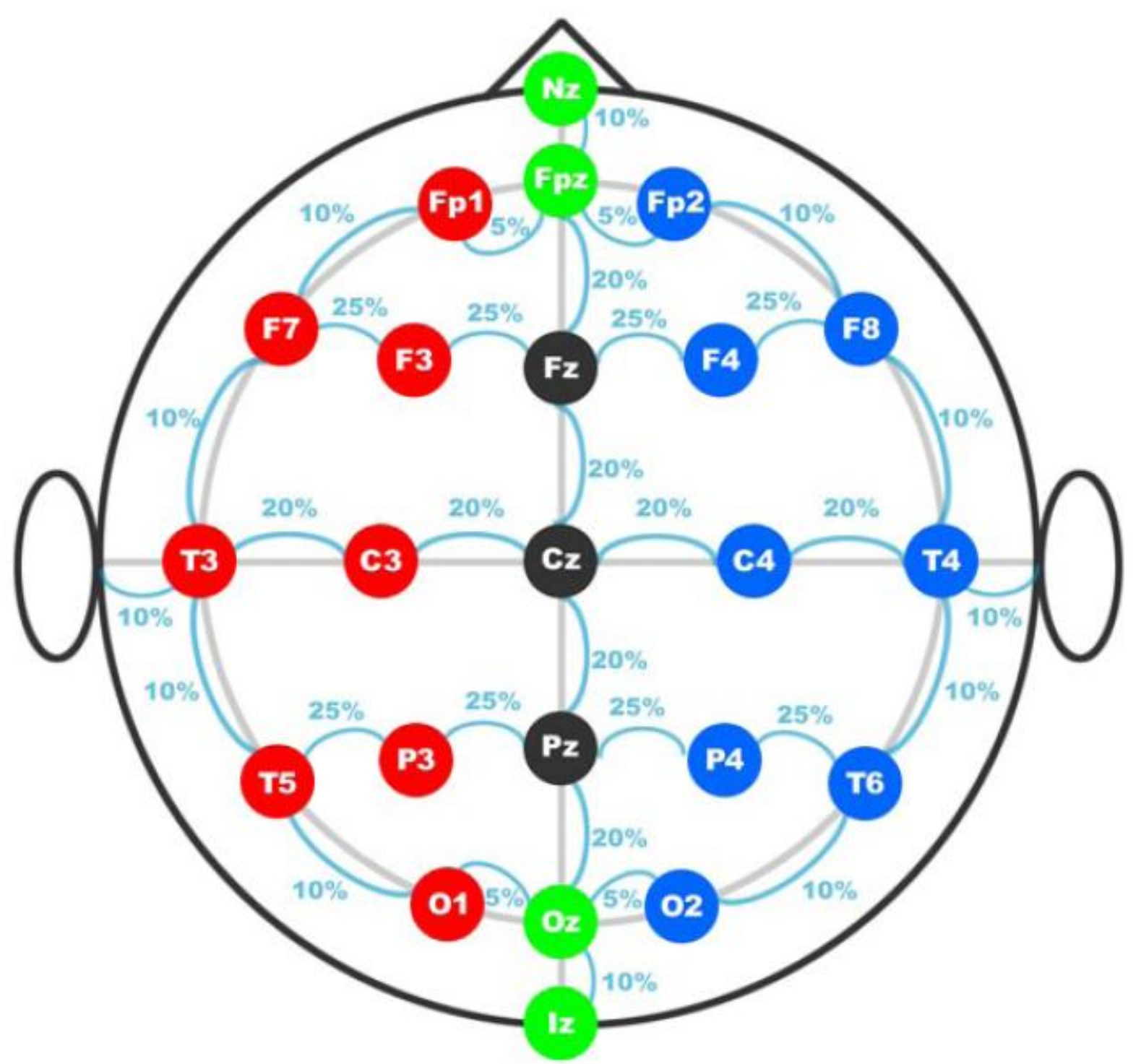

Figura 3 Posicionamento do ânodo em F3 (sistema 10-20). Fonte: Jasper, 1958 (89). 


\subsubsection{Segurança na aplicação da eletroestimulação}

Para gerar uma corrente de estimulação, é necessária uma fonte de energia. Existem duas formas utilizadas na eletroterapia: a energia química armazenada em baterias e a energia gerada por uma rede elétrica (72).

A principal desvantagem dos estimuladores alimentados pela rede é seu potencial para causar choques elétricos lesivos, pois sua voltagem varia de 120 a 227 volts (V). Já as baterias são fontes de corrente direta de baixa intensidade, variam de 1,5 a 12 volts e são mais seguras (72). A fonte de alimentação utilizada na ETCC é a bateria de 9 volts (27).

\subsubsection{Neuromodulação na memória e cognição}

Praticantes regulares de exercícios físicos durante a vida tem probabilidade significativamente menor de desenvolver o Alzheimer em comparação às pessoas inativas (90-92). O exercício físico associado à estimulação cognitiva, funcional e comportamental traz resultados positivos para idosos (93). Kramer et al. (2006) (94), revisaram uma extensa literatura e comprovaram a influência do exercício físico aeróbico sobre o funcionamento cerebral e a cognição, porém não se sabe o quanto o convívio social, o meio ambiente, as atividades de lazer, entre outros, podem contribuir para este ganho. Eles, também, não chegaram à conclusão de qual intensidade, frequência e duração ou associação com outro tipo de exercício é mais benéfica para as funções cerebrais. A associação da utilização da ETCC e do treinamento esportivo (95) sugere ganhos no desempenho físico e cognitivo, mas o uso deve ser cauteloso.

A neuromodulação demonstrou resultados positivos na função motora da mão, aumento da tolerância ao exercício isométrico, da potência, da força de contração voluntária máxima em exercícios isométricos, da força de pinçamento e 
diminuição do tempo de reação (96-100). Mas, ainda há possibilidade de pesquisa para verificar possíveis efeitos da ETCC quando realizada em conjunto com exercícios de reabilitação física e/ou neuropsicológica $(95 ; 101)$. 


\section{OBJETIVOS}

Objetivo geral:

- Verificar se há interferência na memória de trabalho durante a aplicação da ETCC nos indivíduos com mais de 65 anos.

Objetivo específico:

- Verificar se a aplicação da ETCC sobre o córtex pré-frontal dorsolateral esquerdo interfere na memória de trabalho em idosos, avaliada com testes realizados simultaneamente à ETCC. 


\section{HIPÓTESES}

Hipótese 0 - Não há diferença significativa na memória de trabalho durante a estimulação por corrente contínua.

Hipótese 1 - A aplicação concomitante de ETCC é capaz de melhorar o desempenho de idosos em testes de memória de trabalho. 


\section{MÉTODO}

O projeto foi analisado pelo Comitê de Ética em Pesquisa da Faculdade de Ciências da Saúde da Universidade de Brasília (CEP/FS), sob parecer número 1.546.528 e CAAE 53483516.8.0000.0030 (anexo A).

O estudo foi controlado. A seleção dos indivíduos foi realizada através de ligações telefônicas e convite a idosos que participaram anteriormente de projetos realizados pela equipe de pesquisadores do Hospital Universitário de Brasília e Faculdade de Ciências da Saúde, divulgação no Jornal da Universidade de Brasília e nas redes sociais, além de convite feito pessoalmente a grupos comunitários de idosos, como em grupos de ginástica nos parques de Brasília.

Após o convite, o primeiro contato com os idosos foi feito por telefone, assim foi possível averiguar o uso de medicações controladas, entre outros critérios de exclusão, e ainda informar sobre o consumo de cafeína nos dias dos testes.

Os procedimentos foram realizados em ambiente silencioso e reservado. Primeiramente, os participantes assinaram um Termo de Consentimento Livre e Esclarecido (TCLE) (anexo B), com os propósitos e explicações acerca da pesquisa.

$\mathrm{Na}$ primeira sessão, os participantes responderam à ficha de avaliação do idoso (anexo C), na qual se questiona dados demográficos, consumo de cafeína no dia e história pregressa, à Avaliação Cognitiva de Montreal (MoCA) (102-104) (anexo D), em que é possível quantificar o comprometimento cognitivo, e ao Inventário de Depressão de Beck (IDB) (105-108) (anexo E), pois a depressão altera o funcionamento neuronal e impede a participação neste estudo. Os testes neuropsicológicos foram realizados conforme procedimentos já padronizados e descritos na literatura especializada (102-110).

A versão experimental brasileira da avaliação cognitiva de Montreal foi desenvolvida em São Paulo com o objetivo de ser um instrumento breve de rastreio e avalia os idosos em vários aspectos, como nas funções visuoespacial/executiva, nomeação, memória, atenção, linguagem, abstração, evocação tardia e orientação temporal e espacial. O pesquisador tem acesso ao protocolo de aplicação e é 
orientado a não ajudar nas respostas. A pontuação máxima é 30 e o ponto de corte é 26, ou seja, indivíduos que atinjam a pontuação acima de 26 são considerados normais (102-104).

O IDB consiste em vinte e um questionamentos sobre como o indivíduo se sentiu na última semana. Cada questão apresenta quatro alternativas numeradas que variam de intensidade. A numeração de cada questão varia de zero a três e ao final o pesquisador soma a pontuação. $O$ resultado da soma variando de zero a nove indica que o indivíduo não está deprimido; dez a dezoito indicam depressão leve a moderada; dezenove a vinte e nove indicam depressão moderada a severa e acima de trinta indica depressão severa. A pontuação pode chegar a sessenta e três (105108).

No mesmo dia, houve aplicação do teste de sequência de números e letras (Subitem 13) da Escala de Inteligência Wechsler para Adultos, $3^{\underline{a}}$ edição (Escala de WAIS III) (109) (anexo F) com o objetivo de avaliar a memória de trabalho por intermédio de estímulos auditivos, neste teste os participantes ouviam uma sequência embaralhada de números e letras e tinham que repeti-la de forma organizada, falando primeiro os números em ordem crescente e depois as letras em ordem alfabética. Para avaliar a memória de trabalho também por estímulos visuoespaciais, foi realizado o Teste de Cubos de Corsi (TCC) (110) (anexo G), em que uma sequência de cubos era apontada (figura 4) e os participantes tinham que repetir a sequência na mesma ordem (figura 5). O pesquisador dispunha de um gabarito para seguir conforme os números, porém o participante não conseguia visualizá-lo (anexo G). Estes dois testes foram realizados durante a estimulação. A pontuação é referente à quantidade de cubos apontada corretamente na última sequência antes do erro. Os voluntários podiam errar apenas uma vez em cada sequência. $O$ teste era cessado quando o participante errasse duas sequências com o mesmo número de cubos. 


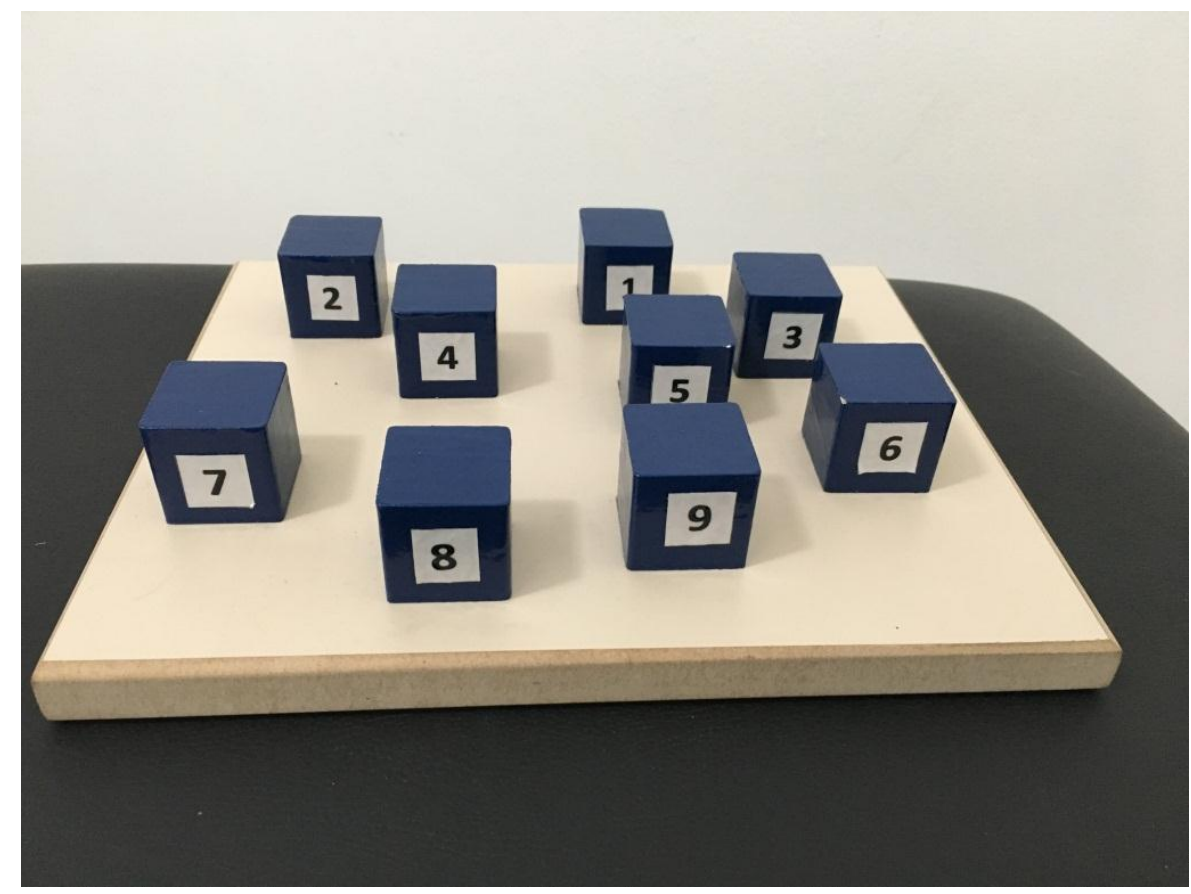

Figura 4 Teste dos Cubos de Corsi visto pelo pesquisador.

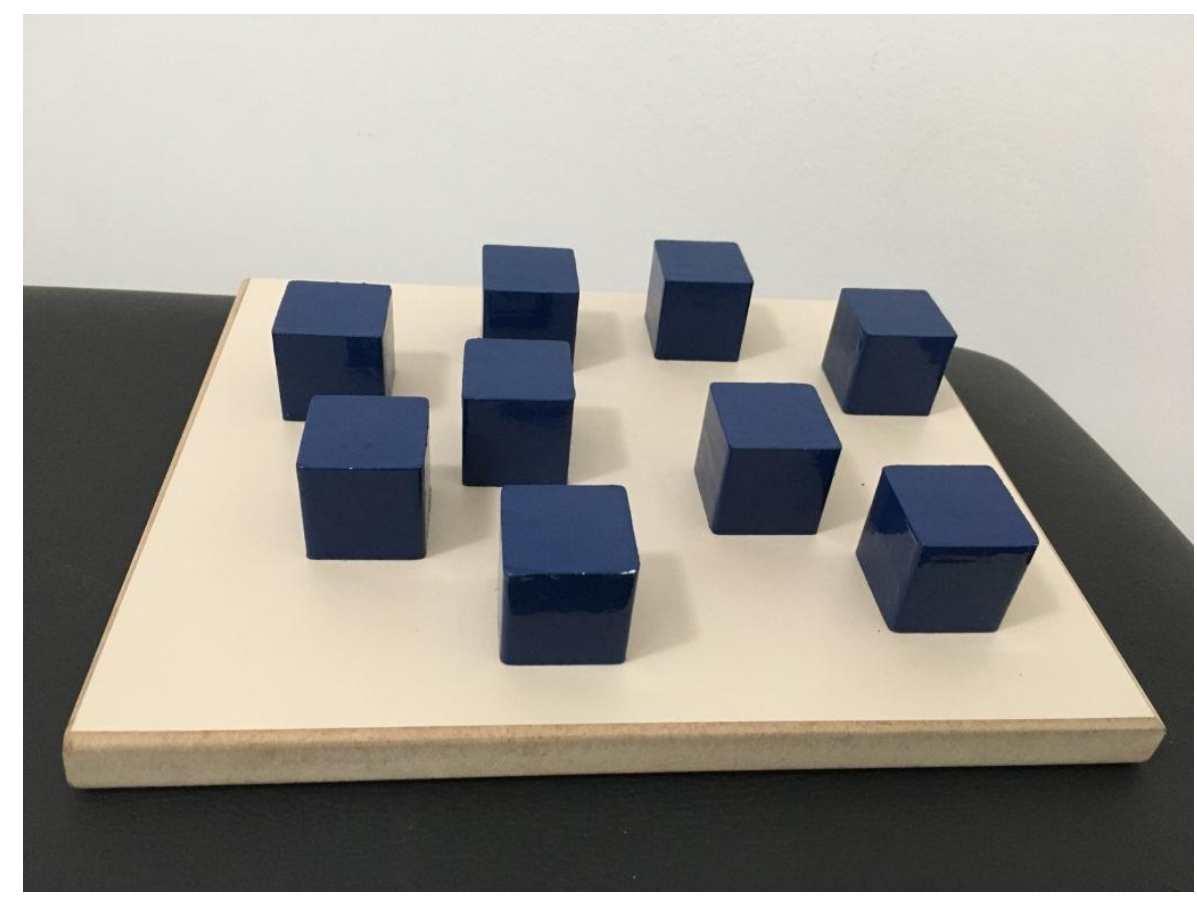

Figura 5 Teste dos Cubos de Corsi visto pelo participante. 
Antes da estimulação, os idosos foram divididos arbitrariamente nos grupos:

Grupo 1 - composto por oito idosos que realizaram, no primeiro dia, estimulação real por 20 minutos. Na semana seguinte, durante a segunda sessão, esses indivíduos foram submetidos à mesma sequência, porém com estimulação fictícia.

Grupo 2 - composto por onze idosos que realizaram a mesma sequência do grupo 1, porém iniciaram com estimulação fictícia e finalizaram com a estimulação real.

Foi utilizado um estimulador de corrente contínua especialmente desenvolvido para estudos científicos. Esse equipamento é alimentado por baterias de $9 \mathrm{~V}$, não havendo riscos de exposição dos voluntários à corrente elétrica de $220 \mathrm{~V}$. A estimulação foi realizada através de eletrodos-esponja embebidos em salina, com área de $15 \mathrm{~cm}^{2}$. O ânodo foi posicionado sobre o córtex pré-frontal dorsolateral esquerdo, em F3 (posição do sistema internacional 10-20 de colocação de eletrodos de eletroencefalografia) (89) e o cátodo sobre o ombro ipsilateral (figura 6). Este posicionamento é chamado de monopolar, em que o eletrodo ativo é colocado sobre o escalpo e o eletrodo de referência é colocado em qualquer região corporal extracefálica, neste caso, no ombro ipsilateral (111). A intensidade da corrente foi de $1,0 \mathrm{~mA}$ e a duração da estimulação de 20 minutos. Cada indivíduo foi seu próprio controle, pois este estudo realizou a comparação entre os resultados obtidos com a estimulação real e a fictícia. A estimulação é imperceptível para o indivíduo, por isso foi possível realizar essa estimulação fictícia. Algumas pessoas relatam sentir um leve formigamento no início da estimulação, então, para realizar a ETCC fictícia sem que a diferença fosse percebida pelos voluntários, eram administrados 20 segundos de estimulação real antes de desligar o aparelho e iniciar a ETCC fictícia. Neste aparelho, há uma chave para interromper a corrente e é possível mostrar o visor ativo com a intensidade da corrente ao participante, sem realmente administrar corrente elétrica. 


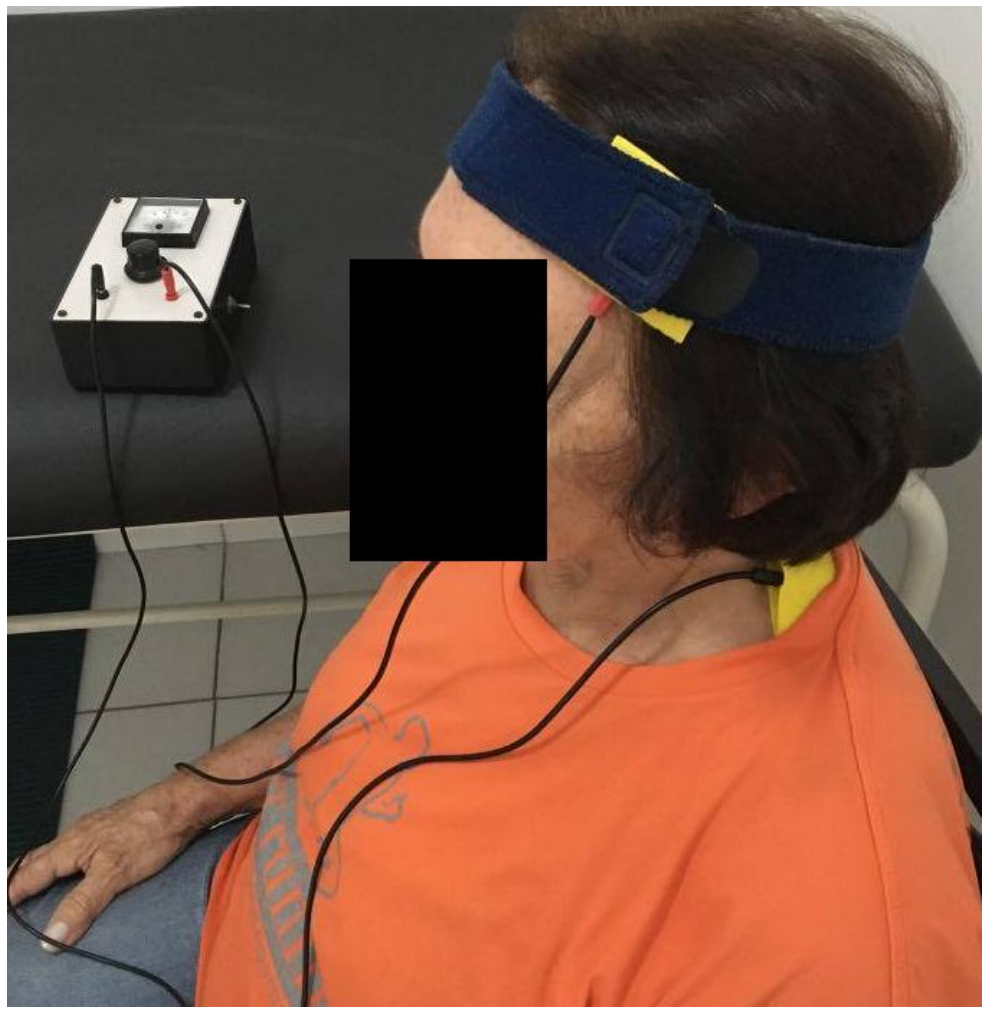

Figura 6 Posicionamento dos eletrodos: ânodo na região de F3, conforme o sistema 10-20 e cátodo no ombro ipsilateral.

Os resultados foram organizados em planilha eletrônica e as análises estatísticas foram tratadas através do software R (versão 3.3.2). 


\section{CRITÉRIOS}

\subsection{CRITÉRIOS DE INCLUSÃO}

- Indivíduos com mais de 65 anos de idade.

\subsection{CRITÉRIOS DE EXCLUSÃO}

- Uso de sedativos, antidepressivos, anticonvulsivantes, amantadina ou memantina durante a pesquisa;

- Consumo de cafeína no dia da estimulação;

- História prévia de acidente vascular cerebral, epilepsia, traumatismo crânioencefálico;

- Diabéticos com complicações e/ou uso de insulina;

- Objetos metálicos no crânio;

- Pessoas submetidas a craniotomia;

- Uso de marca-passo;

- Escolaridade inferior a 8 anos. 


\section{RESULTADOS}

Todos os participantes toleraram bem a estimulação e nenhum desconforto foi relatado. Dezenove participantes de ambos os sexos (7 Homens e12 Mulheres), com idade acima de 65 anos (média de idade 71,32 anos) realizaram inicialmente 0 MoCA e o inventário de depressão de Beck, e durante a ETCC realizaram os testes de Sequência de Números e Letras, subitem 13 da Escala de Inteligência Wechsler para Adultos (Escala de Wais) - 3a edição, e o teste dos Cubos de Corsi durante a estimulação elétrica por corrente contínua.

Nenhum idoso obteve pontuação acima de 9 no Inventário de depressão de Beck, ou seja, os participantes não estavam com sintomas de depressão, portanto todos puderam participar do estudo.

Com relação a pontuação obtida no MoCA, houve uma variação indicando que seis idosos são classificados como normais, enquanto que os outros são classificados como apresentando comprometimento cognitivo leve (figura 7).

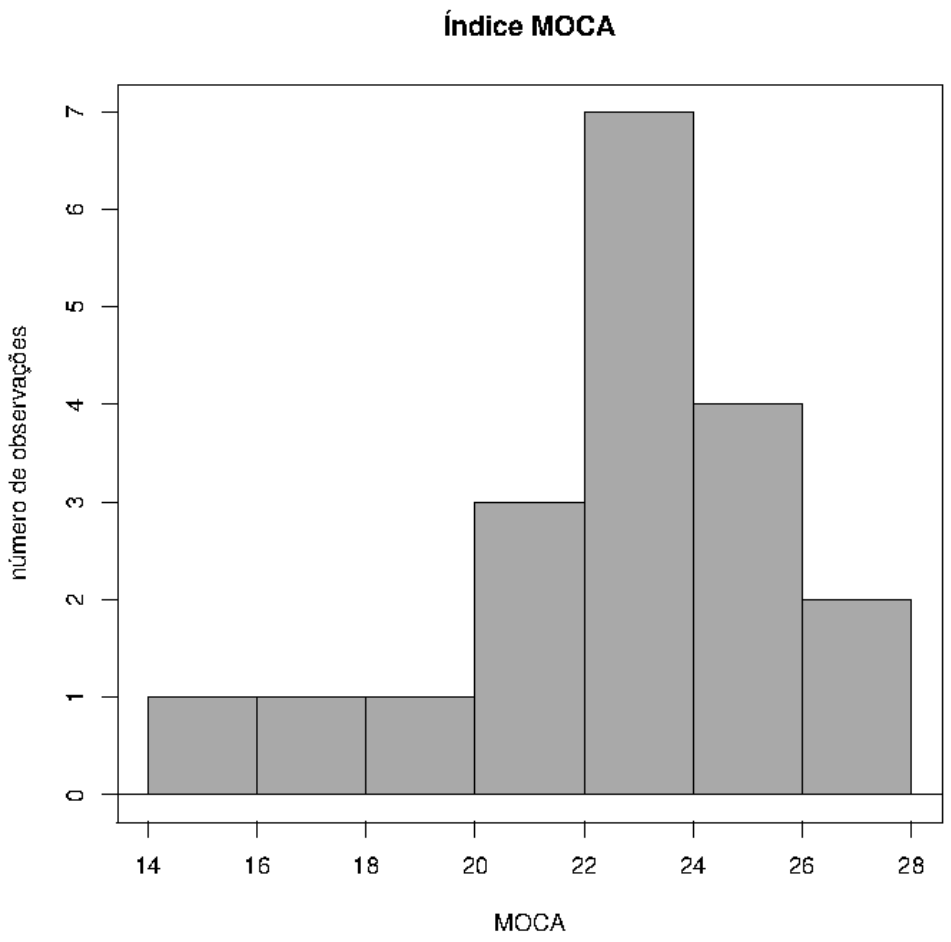

Figura 7 Apresentação da pontuação obtida no MoCA 
Os resultados do MoCA são diretamente proporcionais à idade, conforme ilustra a figura 8.

Índice MOCA em função da idade

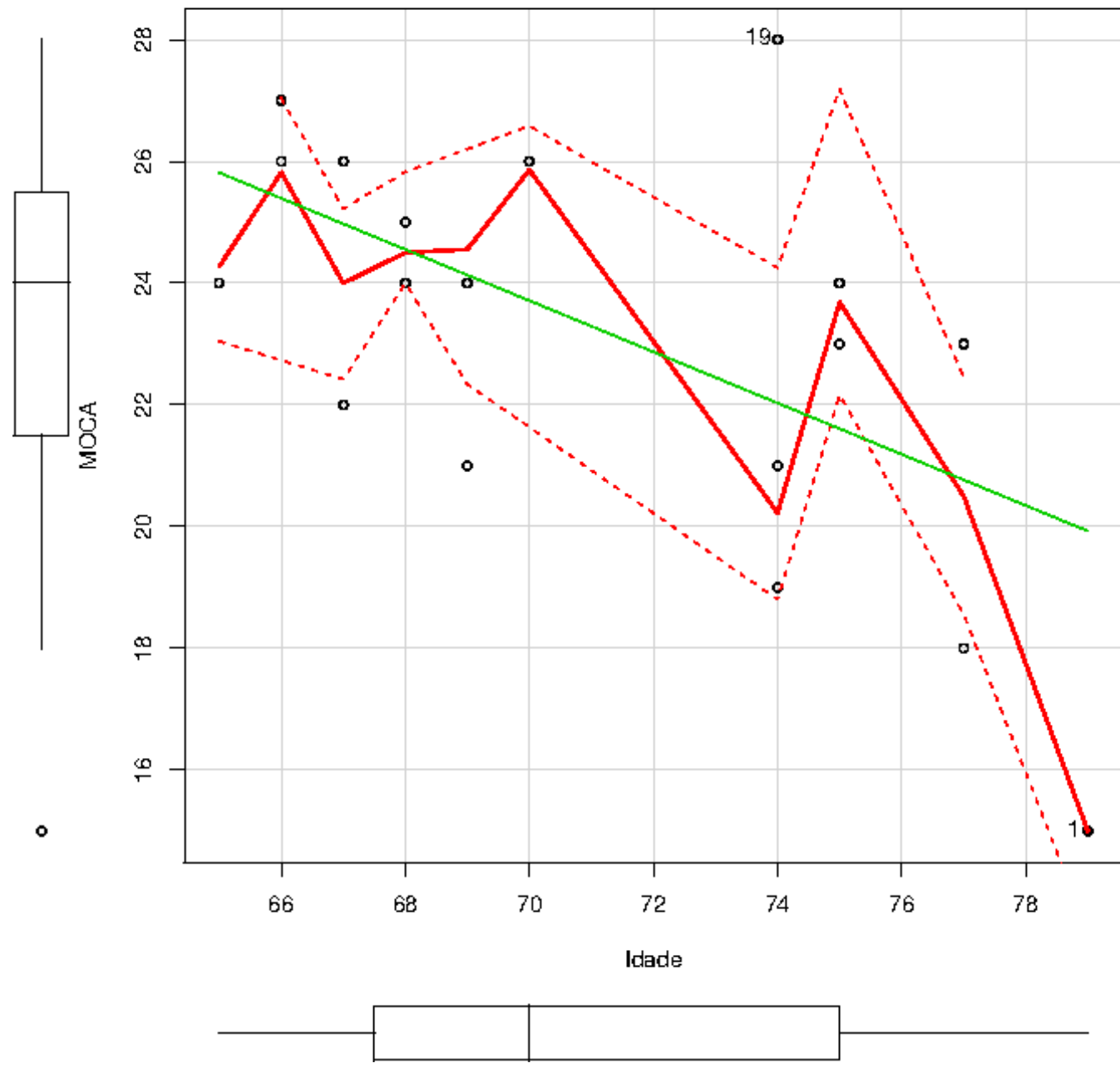

Figura 8 Relação diretamente proporcional entre a pontuação alcançada no MoCA e a idade dos participantes 
MOCA X TCC

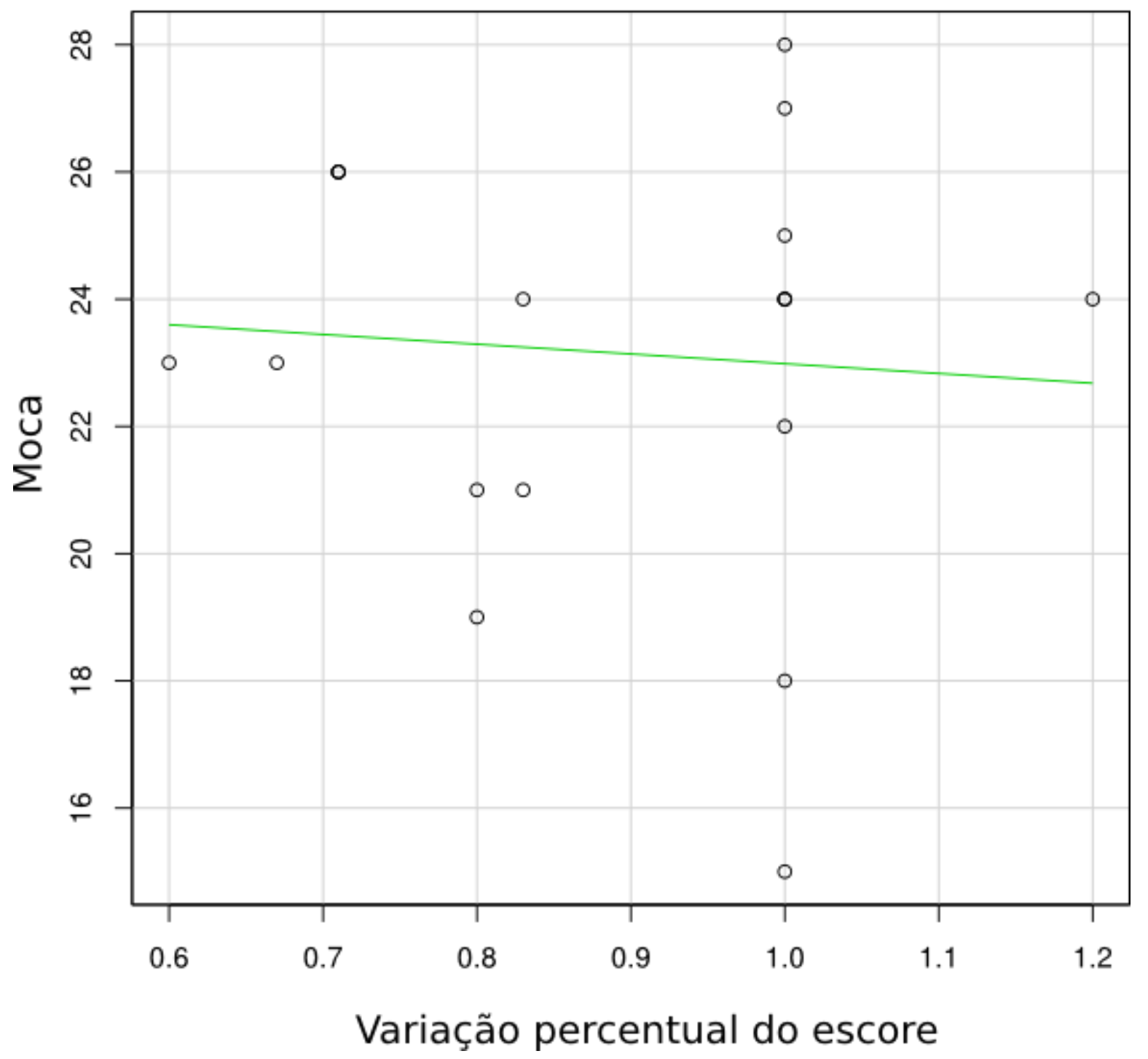

Figura 9 Variação percentual dos escores do TCC sob estimulação real do CPFDL esquerdo em função do índice do MOCA de cada sujeito. Não há correlação significativa entre essas variáveis $\left(r^{2}\right.$ de Pearson $\left.=-0,05\right)$.

Apenas um participante obteve melhor desempenho em ambos os testes durante a estimulação real comparado com o desempenho no dia da estimulação fictícia, como pode ser observado na tabela 1. 
Tabela 1- Desempenho nos testes durante a estimulação transcraniana por corrente contínua anódica

\begin{tabular}{|c|c|c|c|c|}
\hline \multirow[b]{2}{*}{ Sexo } & \multicolumn{2}{|c|}{ Sequência de Números e Letras } & \multicolumn{2}{|c|}{ Cubos de Corsi } \\
\hline & SHAM & REAL & SHAM & REAL \\
\hline $\mathrm{F}$ & 5 & 5 & 5 & 5 \\
\hline M & 7 & 6 & 5 & 5 \\
\hline $\mathrm{F}$ & 8 & 8 & 5 & 3 \\
\hline $\mathrm{F}$ & 8 & 6 & 5 & 5 \\
\hline $\mathrm{F}$ & 8 & 6 & 6 & 6 \\
\hline $\mathrm{F}$ & 9 & 9 & 7 & 5 \\
\hline$F$ & 10 & 9 & 5 & 5 \\
\hline M & 10 & 9 & 6 & 5 \\
\hline M & 11 & 8 & 5 & 5 \\
\hline$F$ & 12 & 12 & 7 & 5 \\
\hline $\mathrm{M}$ & 7 & 9 & 5 & 6 \\
\hline $\mathrm{M}$ & 12 & 12 & 7 & 5 \\
\hline$F$ & 10 & 10 & 6 & 6 \\
\hline$F$ & 6 & 7 & 4 & 4 \\
\hline $\mathrm{M}$ & 8 & 10 & 6 & 6 \\
\hline$F$ & 7 & 8 & 6 & 5 \\
\hline $\mathrm{M}$ & 7 & 9 & 5 & 4 \\
\hline$F$ & 10 & 7 & 5 & 4 \\
\hline$F$ & 9 & 8 & 6 & 4 \\
\hline
\end{tabular}


$\mathrm{Na}$ sequência de números e letras, seis participantes mantiveram o mesmo desempenho e oito idosos apresentaram pior desempenho durante a estimulação real, como podem ser observados na tabela 1, os outros apresentaram pontuação mais baixa no dia da aplicação da ETCC fictícia. Este resultado não foi estatisticamente significante $(p=0,7486)$.

No teste dos Cubos de Corsi, nove resultados foram iguais, independentemente da estimulação, nove pessoas apresentaram pior desempenho durante a estimulação real, e apenas um alcançou maior pontuação durante a ETCC real (tabela 1). A análise estatística desses resultados mostra que, realmente, durante a estimulação, os idosos não apresentam melhora no desempenho deste teste, mas, sim, uma piora ( $p=0,00552)$ (figura 10).

Na figura 10, é possível observar a discrepância dos resultados do TCC com a ETCC fictícia e a ETCC real, que é estatisticamente significativa, bem como a semelhança das médias da pontuação na SLN com a ETCC real e fictícia. Na figura 11 é notável a influência da ETCC no desempenho no TCC.

Ao compararmos os efeitos da ETCC sobre os resultados obtidos no TCC com a pontuação alcançada no MoCA, não houve relação estatística, conforme mostrado na figura 9. Isso sugere que o comprometimento cognitivo prévio não predispõe o sujeito aos efeitos deletérios da ETCC "online" sobre o desempenho no TCC. 


\section{ETCC do CPFDL esquerdo}

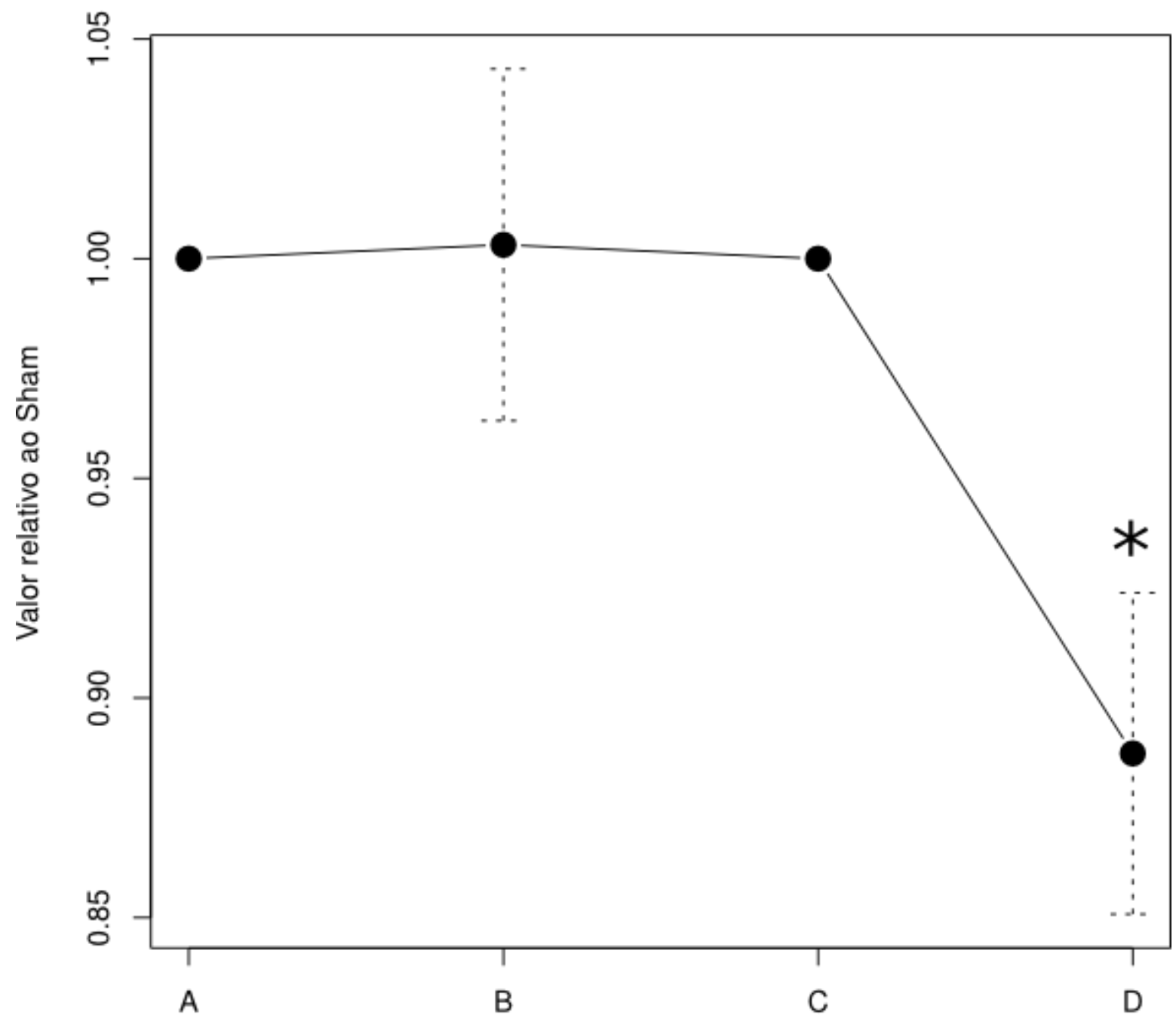

Condição experimental

Figura 10 Variação média dos escores no Teste de Sequência de Letras e Números e no Teste dos Cubos de Corsi durante a estimulação real em comparação com a fictícia ("Sham"). Para cada sujeito, o escore obtido durante a estimulação "Sham" foi considerado igual a 1,0. As barras de erro indicam o erro-padrão das médias. (A) Sham, sequência de letras e números; (B) Real, sequência de letras e números; (C) Sham, Cubos de Corsi; (D) Real, Cubos de Corsi. * $\mathrm{p}<0,01$ 
Influência da ETCC no TCC

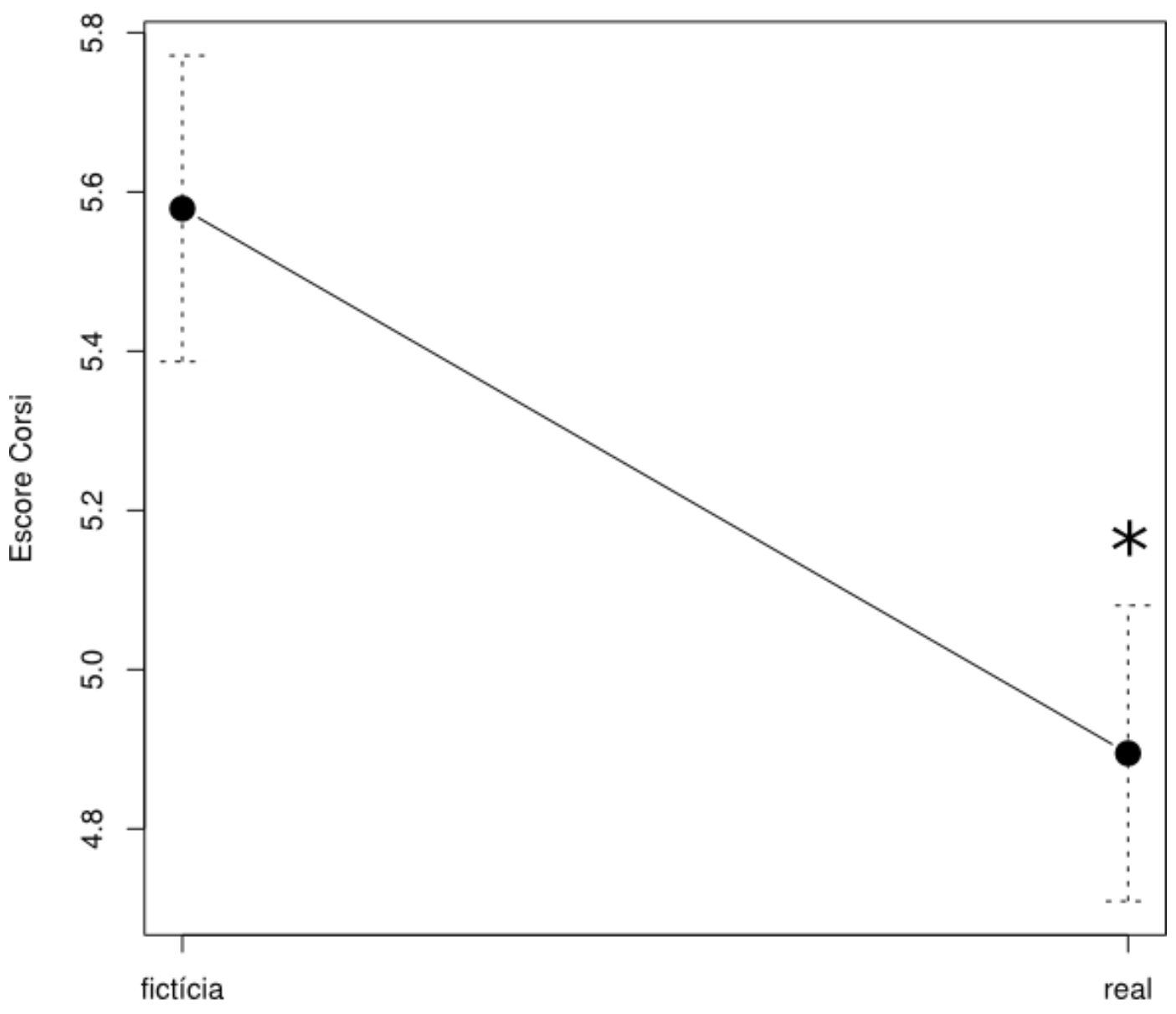

Condição experimental

Figura 11 Médias dos escores no Teste dos Cubos de Corsi sob estimulação fictícia e sob ETCC real do córtex pré-frontal dorsolateral esquerdo. Observa-se uma queda significativa da performance dos voluntários sob estimulação real $(p<0,01)$. As barras de erro representam o erro-padrão da média. 


\section{DISCUSSÃO}

Além dos estudos que evidenciaram melhora em funções cognitivas com a ETCC, citados na Introdução, alguns estudos têm demonstrado que tanto a EMT quanto a ETCC, aplicadas sob certas condições, são capazes de interferir com a fisiologia normal das redes neurais, produzindo perturbação ou disrupção temporárias da cognição, fenômeno esse que Pascual-Leone (2000) (12) compara a uma verdadeira "lesão virtual", que seria útil para determinar a função de diferentes áreas corticais, contribuindo, assim, para o desenvolvimento da neuropsicologia.

Enquanto vários estudos com ETM repetitiva conseguiram produzir essa "lesão virtual", poucos estudos utilizaram a ETCC com essa finalidade. Por exemplo, Panico et al (2016) (112) demonstraram que a ETCC catódica do cerebelo interfere na recalibração e no realinhamento espacial durante o procedimento de adaptação a prismas em indivíduos normais. Na mesma linha, van Elk et al (2016) (113) evidenciaram que a ETCC anódica "online" da junção temporoparietal direita perturbava uma tarefa de rotação espacial mental do próprio corpo projetado num avatar apresentado numa tela de computador.

Com relação aos estudos sobre o efeito da ETCC sobre a memória, apenas um estudo foi capaz de produzir disrupção dos processos de memória: Zwissler et al (2014) (114) demonstraram que a ETCC anódica do CPFDLe pode induzir a formação de falsas memórias em testes de memória episódica. É interessante notar que $o$ alvo e a polaridade da estimulação, nesse estudo, foram os mesmos que os utilizados no presente trabalho. Esses efeitos da ETCC anódica sobre o CPFDLe sugerem que $\mathrm{o}$ aumento da excitabilidade neuronal pode estar associado à perda de detalhes do estímulo durante a fase de codificação da memória.

Steenbergen et al (2015) (115) testando um equipamento comercialmente disponível, produzido industrialmente e voltado para o público leigo (Foc.us $\AA$ ), verificou que tanto a estimulação "online" quanto a "off-line" prejudicava a performance de indivíduos jovens normais em teste de memória operacional. 
Nos testes realizados no presente estudo, a alça fonológica (46) é importante para o desempenho no teste de sequência de números e letras, ao passo que o teste dos cubos de Corsi claramente necessita do esboço visuoespacial.

Os voluntários participantes desta pesquisa apresentaram, durante a ETCC anódica do CPFDLe, uma dissociação dos resultados dos testes dependentes da alça fonológica e do esboço visuoespacial, respectivamente, SLN e TCC. Enquanto estes últimos foram significativamente alterados, os primeiros não sofreram alteração significativa. Esses resultados evocam o caso clínico descrito por Hanley et al (1991) (116), da paciente ELD. Após uma cirurgia de aneurisma do hemisfério cerebral direito, ELD passou a apresentar dificuldades com o TCC, dificuldade de reconhecer faces de pessoas às quais ela tinha sido apresentada após a doença, incluindo faces de pessoas que haviam se tornado famosas recentemente. Em contraste, ela não tinha problemas com testes de memorização de letras e fonemas e conseguia se lembrar dos nomes de pessoas recentemente conhecidas. Segundo Hanley e cols (1991) (116), ELD apresentava uma disfunção seletiva do esboço visuoespacial, com preservação da alça fonológica. É notável, entretanto, que a ETCC anódica foi realizada nos voluntários idosos testados, sobre o hemisfério cerebral esquerdo.

Um recente estudo (117) evidenciou, durante a ressonância nuclear magnética funcional (RNMf), uma ativação importante do hemisfério esquerdo durante a realização do teste dos cubos de Corsi em voluntários normais (média de idade 24,7 anos). Foi evidenciada ativação dos giros temporal inferior, lingual, fusiforme e occipital médio.

Do mesmo modo, Duncan e Owen (2000) (118), em um trabalho de revisão, chamam a atenção para a multiplicidade de regiões recrutadas bilateralmente nos lobos frontais por diversas tarefas cognitivas não relacionadas. Esses achados enfatizam a participação bilateral dos lobos frontais em muitas funções cognitivas (figura 12). É possível, portanto, em vista desses achados de neuroimagem, que o CPFDLe desempenhe um papel importante na codificação dos estímulos do TCC. 


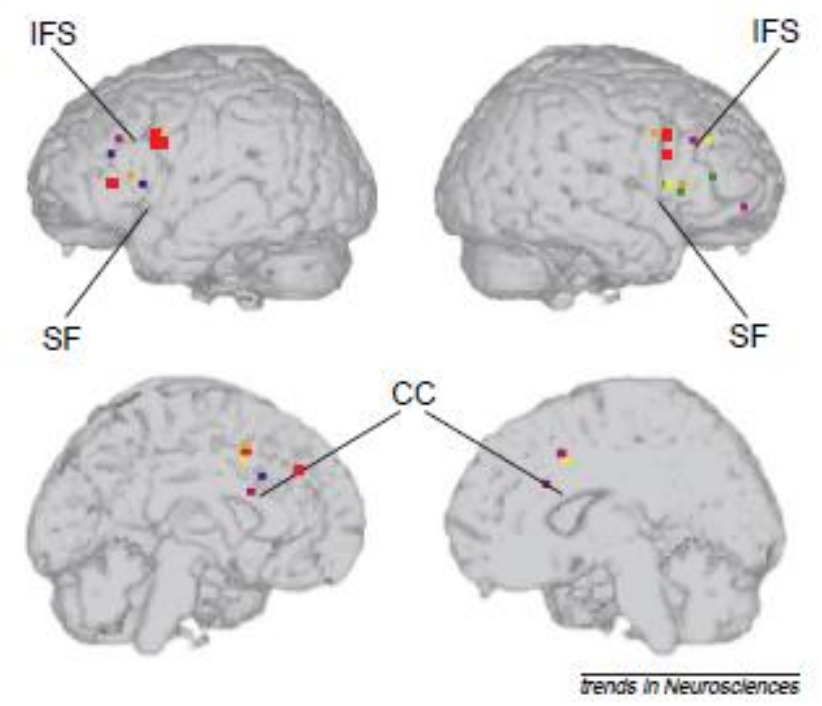

Figura 12 Múltiplas regiões frontais ativadas por tarefas cognitivas bastante diferentes, relacionadas à discriminação auditiva (pontos verdes); atenção visual dividida (pontos azuis); modificação de tarefas (pontos alaranjados); solução de problemas espaciais (pontos rosas); e processamento semântico de palavras (pontos vermelhos). Fonte: Duncan e Owen, 2000 (118).

O aumento de excitabilidade do CPFDLe, que sugerimos como a causa da disrupção da performance no TCC, provavelmente produziu efeito deletério sobre a fase de codificação dos estímulos. Nenhuma outra região cerebral foi estimulada, já que utilizamos uma montagem monopolar com referência extracefálica conforme a classificação proposta por Nasseri et al (2015) (111). A codificação dos detalhes visuoespaciais dos estímulos apresentados durante o teste de cubos de Corsi pode ter sido prejudicada pelo aumento da excitabilidade do CPFDLe induzida pela ETCC anódica "online", do mesmo modo descrito por Zwissler et al (2014) (114), no seu estudo sobre indução de falsas memórias pela ETCC.

É interessante observar que o teste de SNL, dependente da alça fonológica, não foi significativamente afetado, indicando uma maior resistência desses circuitos neurais à perturbação produzida pela ETCC.

Os possíveis efeitos colaterais cognitivos da ETCC têm sido amplamente negligenciados, porém, como destacam luculano e Kadosh, devem ser pesquisados sistematicamente, já que melhoras de desempenho podem ocorrer à custa de prejuízo em outros domínios da cognição. Em nosso estudo, não podemos excluir a 
possibilidade de que tenha ocorrido a inibição do hemisfério cerebral direito decorrente da estimulação anódica à esquerda (119).

Outro aspecto que necessita ser abordado, é o fato de os voluntários do presente estudo serem idosos, e alguns até preenchendo o critério de MoCA para comprometimento cognitivo leve, o que pode ter resultado em uma maior susceptibilidade aos efeitos de perturbação pela ETCC anódica. Não foram avaliados os efeitos "off-line" da ETCC, não sendo possível descartar uma posterior melhora da performance, até mesmo a níveis superiores à fase de pré-estimulação, como foi demonstrado em estudos com voluntários jovens $(17 ; 26)$. 


\section{CONCLUSÕES}

Com relação aos objetivos do trabalho foi possível concluir que:

1) há interferência na memória de trabalho durante a aplicação da ETCC nos indivíduos com mais de 65 anos;

2) a interferência afeta seletivamente a função do esboço visuoespacial, testado pelo teste cubos de Corsi;

3) a alça fonológica, testada pelo teste de sequência de letras e números, mostrou-se resistente à perturbação produzida pela estimulação anódica;

4) idosos podem ser um subgrupo de indivíduos especialmente susceptíveis à disrupção de funções neurais corticais pela aplicação "online" da ETCC;

5) este é o primeiro estudo na literatura a demonstrar disrupção de aspectos da memória de trabalho pelo ETCC.

\subsection{LIMITAÇÕES DO ESTUDO}

Uma das limitações deste estudo é a avaliação apenas em uma sessão e durante a estimulação. Logo, sugere-se um acompanhamento após a estimulação, já que estudos anteriores demonstraram uma melhora do desempenho após a cessação da estimulação. 


\section{REFERÊNCIAS BIBLIOGRÁFICAS}

1. Alzheimer's Disease International. World Alzheimer Report. 2015. http://www.alz.co.uk/research/WorldAlzheimerReport2015.pdf (acessado em 12 setembro 2015).

2. Alzheimer's Disease International.World Alzheimer Report.2012. http://www.alz.co.uk/research/WorldAlzheimerReport2012.pdf (acessado em 14 maio 2014).

3. Castro, DM, et al. The economic cost of Alzheimer's disease: family or publichealth burden? Dement Neuropsychol 2010;4(4):262-267

4. Fuentes P. Funcionalidad y demencia. Rev HospClinUniv Chile 2008;19(4):324-9.

5. Petersen RC. Mild cognitive impairment as a diagnostic entity. Journal of Internal Medicine 2004;256(3):183-194.

6. Daly E; Zaitchik D; Copeland M; Schmahmann J; Gunther J; Albert M. Predicting conversion to alzheimer disease using standardized clinical information. Arch Neurol 2000;57(5):675-680.

7. Petersen R; Negash S. Mild cognitive impairment: an overview. CNS Spectrums 2008;13(1):45-53.

8. Marra, et al. Transcranial magnetic stimulation to address mild cognitive impairment in the elderly: a randomized controlled study. Behavioural Neurology 2015; 2015: 1-13.

9. Lee J; Choi B; Oh E; Sohn E; Lee A. Treatment of alzheimer's disease with repetitive transcranial magnetic stimulation combined with cognitive training: $A$ prospective, randomized, double-blind, placebo-controlled study. J ClinNeurol 2015;11(e-34).

10.Brunoni A, et al. Neuromodulation approaches for the treatment of major depression: Challenges and recommendations from a working group meeting. ArqNeuropsiquiatr 2010;68:433-451.

11. Priori A. Brain polarization in humans: a reappraisal of an old tool for prolonged non-invasive modulation of brain excitability. Clinical Neurophysiology 2003;114:589-595. 
12. Pascual-Leone A; Rubio B; Pallardo F; Catala M. Rapid-rate transcranial magnetic stimulation of left dorsolateral prefrontal cortex in drug-resistant depression. Lancet 1996;348(9022):233-237.

13. Fregni $F$, et al. Treatment of major depression with transcranial direct current stimulation. Bipolar Disord 2006;8:203-204.

14. Nguyen $\mathrm{J}$, et al. Motor cortex stimulation in the treatment of central and neuropathic pain. Arch Med Res 2000;31(3):263-265.

15. Fregni $F$, et al. A sham-controlled, phase II trial of transcranial direct current stimulation for the treatment of central pain in traumatic spinal cord injury. Pain 2006;122:197-209.

16. Boggio P; Nunes A; Rigonatti S; Nitsche M; Pascual-Leone A; Fregni F. Repeated sessions of noninvasive brain DC stimulation is associated with motor function improvement in stroke patients. RestorNeurolNeurosci 2007;25(2):123-129.

17. Javadi AH; Walsh V. Transcranial direct current stimulation (tDCS) of the left dorsolateral prefrontal cortex modulates declarative memory. Brain Stimul 2012;5(3):231-241.

18. Márquez-Ruiz J, et al. Transcranial direct-current stimulation modulates synaptic mechanisms involved in associative learning in behaving rabbits. PNAS 2012 Apr;109(17):6710-6715.

19.Baker J; Rorden C; Fridriksson J. Using transcranial direct-current stimulation to treat stroke patients with aphasia. Stroke 2010;41:1229-1236.

20.Boggio PS, Khoury LP, Martins DCS, Martins OEMS, Macedo EC, Fregni F. Temporal cortex direct current stimulation enhances performance on a visual recognition memory task in Alzheimer disease. J NeurolNeurosurg Psychiatry 2009;80:444-447.

21.Sandrini M, Brambilla M, Manenti R, Rosini S, Cohen LG, Cotelli M. Noninvasive stimulation of prefrontal cortex strengthens existing episodic memories and reduces forgetting in the elderly. Front Aging Neurosci 2014 Oct;6(289):1-9.

22. Brunelin J, et al. Examining transcranial direct-current stimulation (tDCS) as a treatment for hallucinations in schizophrenia. Am J Psychiatry 2012 Jul;169:719724.

23. Nitsche MA, Paulus W. Excitability changes induced in the human motor cortex by weak transcranial direct current stimulation. J Physiol 2000 Set;527(3):633-9. 
24. Nitsche MA, et al. Shaping the effects of transcranial direct current stimulation of the human motor cortex. J Neurophysiol 2007;97:3109-3117.

25. Antal A, Kincses TZ, Nitsche MA, Paulus W (2003) Manipulation of phosphine thresholds by transcranial direct current stimulation in man. Exp Brain Res 2003;150:375-378.

26. Fregni $F$, et al. Anodal transcranial direct current stimulation of prefrontal cortex enhances working memory. Exp Brain Res 2005;166(1):23-30.

27. Nitsche MA, et al. Transcranial direct current stimulation: state of the art 2008 . Brain Stimul 2008;1:206-23.

28. Dieckhöfer A, et al. Transcranial direct current stimulation applied over the somatosensory cortex: Differential effect on low and high frequency SEPs. ClinNeurophysiol 2006;117:2221-7.

29. Tanaka T, et al. Transcranial direct-current stimulation increases extracellular dopamine levels in the rat striatum. Front SystNeurosci 2013 Apr;7(6):1-8.

30. Brasil-Neto J. Learning, memory, and transcranial direct current stimulation. Front Psychiatry 2012;3:80.

31. Ganong WF. Fisiologia médica. $5^{a}$ ed. São Paulo: Atheneu; 1989. "Funções superiores do sistema nervoso": reflexos condicionados, aprendizado e fenômenos correlacionados p. 225-235.

32. Tortora GJ, GrabowskySR. Princípios de anatomia e fisiologia. 9a ed. Rio de Janeiro: Guanabara Koogan; 2002.Sistemas sensoriais, motores e integrativos Funções integrativas do cérebro - aprendizado e memória p. 456-569.

33. Machado A. Neuroanatomia funcional. 2 $2^{\underline{a}}$ ed. São Paulo: Atheneu; 1993. Estrutura e funções do córtex cerebral p. 257-274.

34. Machado A. Neuroanatomia funcional. 2 ${ }^{\underline{a}}$ ed. São Paulo: Atheneu; 1993. Áreas encefálicas relacionadas com as emoções p. 275-286.

35.Fuster J. The prefrontal cortex. $5^{\mathrm{a}}$ ed. London: Elsevier; 2015. Animal Neuropsychology. Cognitive Function p.142-156.

36. Charness ME, De La Paz RL. Mamillary body atrophy in Wernicke's encephalopathy: antemortem identification using magnetic resonance imageng. Ann. Neurol1987;22:595-600. In Zubaran, et al. Aspectos clínicos e neuropatológicos da síndrome de Wernicke-Korsakoff. Ver Saúde Pública 1996;30(6):602-8. 
37.Lishman WA. Alcohol and the brain. Br. J. Psychiatr 1990:156:635-44. In Zubaran, et al. Aspectos clínicos e neuropatológicos da síndrome de WernickeKorsakoff. Rev Saúde Pública 1996;30(6):602-8.

38. Fuster J. The prefrontal cortex. $5^{\mathrm{a}}$ ed. London: Elsevier; 2015. Animal Neuropsychology. Emotional Behavior p. 137-141.

39. Wagner $A D$, et al. Material specific lateralization of prefrontal activation during episodic encoding and retrieval. Neuroreport 1998;9:3711-3717.

40.Rugg MD, Wilding EL. Retrieval processing and episodic memory. Trends CognSci 2000;4:108-115.

41. Buckner RL, Wheeler ME, Sheridan MA. Encoding processes during retrieval tasks. J CognNeurosci 2001;13:406-415.

42. Fletcher PC, Henson RN. Frontal lobes and human memory: insights from functional neuroimaging. Brain 2001;124:849-881.

43. Cabeza R, Nyberg L. Functional neuroimaging of memory. Neuropsychologia 2003;41:241-244.

44. Cabeza R, Locantore JK, Anderson ND. Lateralization of prefrontal activity during episodic memory retrieval: evidence for the production-monitoring hypothesis. J. Cogn. Neurosci 2003;15:249-259.

45.Simons JS, Spiers HJ. Prefrontal and medial temporal lobe interactions in longterm memory. Nat Rev Neurosci 2003;4:637-648.

46. Baddeley A. Working memory: looking back and looking forward. Nat Rev Neurosci. 2003;4(10):829-39.

47. Grady CL, et al. Age-related reductions in human recognition memory due to impaired encoding. Science 1995;269:218-221.

48.Grady CL, et al. Age-related changes in regional cerebral blood flow during working memory for faces. Neuroimage 1998;8:409-425.

49. Cabeza R, et al. Age-related differences in neural activity during item and temporal order memory retrieval: a positron emission tomography study. J CognNeurosci 2000;12:197-206.

50. Cabeza R, et al. Age-related differences in neural activity during memory encoding and retrieval: a positron emission tomography study. JNeurosci 1997;17:391-400. 
51.Dennis NA, et al. Effects of aging on the neural correlates of successful item and source memory encoding. J. Exp. Psychol. LearnMemCogn 2008;34:791-808.

52. Gutchess $A H$, etal.Aging and the neural correlates of successful picture encoding: frontal activations compensate for decreased medial- temporal activity. J CognNeurosci 2005;17:84-96.

53. Rosen AC, et al. Variable effects of aging on frontal lobe contributions to memory. Neuroreport 2002;13:2425-2428.

54.Schacter DL, et al. The role of hippocampus and frontal cortex in age-related memory changes: a PET study. Neuroreport 1996;7:1165-1169.

55. Tulving $E$, et al. Hemispheric encoding/retrieval asymmetry in episodic memory: positron emission tomography findings. ProcNatlAcadSci USA 1994;91:20162020.

56. Cabeza R. Hemispheric asymmetry reduction in older adults: the HAROLD model. Psychol Aging2002;17:85-100.

57. Thomas V. Excess functional disability among demented subjects? Dement GeriatrCogn 2001;12:206-210.

58. Petersen RC, Smith GE, Waring SC, et al. Aging, memory, and mild cognitive impairment. IntPsychogeriatr 1997;9:65-9.

59. Winblad B, Palmer K, Kivipelto M, Jelic V, Fratiglioni L, Wahlund LO, et al. Mild cognitive impairment - beyond controversies, towards a consensus: report of the International Working Group on Mild Cognitive Impairment. J Intern Med 2004;256(3):240-6.

60. Portet $\mathrm{F}$, et al. Mild cognitive impairment $(\mathrm{MCl})$ in medical practice: a critical review of the concept and new diagnostic procedure. Report of the MCI Working Group of the European Consortium on Alzheimer's Diasease. J NeurolNeurosurg Psychiatry 2006;77:714-718.

61.Scheller E, Minkova L, Leitner M, Klöppel S. Attempted and successful compensation in preclinical and early manifest neurodegeneration - a review of task fMRI studies. Frontiers in Psychiatry 2014;5(132):1-16.

62. Cabeza R, Mclntosh AR, Tulving E, Nyberg L, Grady CL. Age-related differences in effective neural connectivity during encoding and recall. Neuroreport1997;8:3479-83. 
63. Grady CL, Maisog JM, Horwitz B, Ungerleider LG, Mentis MJ, Salerno JA, et al. Age-related changes in cortical blood flow activation during visual processing off aces and location. J Neurosci1994;14:1450-62.

64.Zago S, Ferrucci R, Fregni F, Priori A. Bartholow, Sciamanna, Alberti: pioneers in the electrical stimulation of the exposed human cerebral cortex. The Neuroscientist 2008;14(5):521-528.

65. Utz KS, Dimova V, Oppenländer K, Kerkhoff G. Electrified minds: transcranial direct current stimulation (tDCS) and galvanic vestibular stimulation (GVS) as methods of non-invasive brain stimulation in neuropsychology - a review of current data and future implications. Neuropsychologia 2010;48(10):2789-2810.

66. Brazier MA. The history of the electrical activity of the brain as a method for localizing sensory function. Medical history 1963;7(3):199.

67. Parent A. Giovanni Aldini: from animal electricity to human brain stimulation. The Canadian Journal of Neurological Sciences 2004;31(4):576-584.

68. Bindman LJ, Lippold, O, Redfearn J. The action of brief polarizing currents on the cerebral cortex of the rat (1) during current flow and (2) in the production of longlasting after-effects. The Journal of physiology 1964,172(3):369-382.

69. Purpura DP, Mcmurtry JG. Intracellular activities and evoked potential changes during polarization of motor cortex. Journal of Neurophysiology 1965;28(1):166185.

70.Priori A, Berardelli A, Rona S, Accornero N, Manfredi M. Polarization of the human motor cortex through the scalp. Neuroreport 1998 Jul;9(10):2257-60.

71.Paulus W, Antal A, Nitsche MA. Physiological basis and methodological aspects of transcranial electric stimulation (tDCS, tACS, and tRNS). In: Miniussi C, Paulus W, Rossini PM. Trasncranial brain stimulation. Boca Raton: Frontiers in Neuroscience; 2013. p. 93-106.

72. Nelson RM, et al. Eletroterapia clínica. 3a Ed. Barieri-SP: editora Manole, 2003. Instrumentação e segurança do produto p. 15-54.

73. Nelson RM, et al. Eletroterapia clínica. 3aㅡ Ed. Barieri-SP: editora Manole, 2003. Revisão da fisiologia p. 3-14.

74. Hattori Y, Moriwaki A Hori Y. Biphasic effects of polarizing current on adenosinesensitive generation of cyclic AMP in rat cerebral cortex. NeurosciLett 1990;116:320-324. 
75. Islam N, et al. Anodal polarization induces protein kinase C Y (PKCY)-like immunoreactivity in the rat cerebral cortex. Neurosci Res 1994;21:169-172.

76. Islam $\mathrm{N}$, et al. Increase in the calcium level following anodal polarization in the rat brain. Brain Res 1995;684:206-208.

77. Marquez-Ruiz J, et al. Transcranial direct-current stimulation modulates synaptic mechanisms involved in associative learning in behaving rabbits. PNAS 2012;109(17):6710-5.

78. Nelson RM, et al. Eletroterapia clínica. 3를 Ed. Barieri-SP: editora Manole, 2003. Os princípios da estimulação elétrica p. 55-140.

79. Fregni $F$, et al. Effects of transcranial direct current stimulation coupled with repetitive electrical stimulation on cortical spreading depression. Exp Neurol. 2007;204(1):462-6.

80. O'Connell NE, et al. Non-invasive brain stimulation techniques for chronic pain. Cochrane Database Syst Rev. 2010;9:CD008208.

81. Berlim M, Neto V, Turecki G. Estimulação transcraniana por corrente direta: uma alternativa promissora para o tratamento da depressão maior? Rev Bras Psiquiatr. 2009;31(1):S34-8.

82. Paulus W. Transcranial direct current stimulation (tDCS). Suppl Clin Neurophysiol. 2003;56:249-54.

83. Boggio PS, et al. Non-invasive brain stimulation to assess and modulate neuroplasticity in Alzheimer's disease. Neuropsychol Rehabil. 2011 ;21(5):703-16.

84.Stagg CJ, et al. Polarity-Sensitive Modulation of Cortical Neurotransmitters by Transcranial Stimulation. Journal of Neuroscience. 2009;29(16):5202-5206.

85. Liebetanz D, et al. Pharmacological approach to the mechanisms of transcranial DC-stimulation-induced aftereffects of human motor cortex excitability. Brain 2002;125:2238-2247.

86. Nitsche, MA; et al. Modulation of cortical excitability by weak direct current stimulation--technical, safety and functional aspects. SupplClinNeurophysiol 2003;56:255-276.

87. Nitsche, MA. Safety criteria for transcranial direct current stimulation (tDCS) in humans.ClinNeurophysiol 2003;114(11):2220-2. 
88. Khedr EM, et al. A double-blind randomized clinical trial on the efficacy of cortical direct current stimulation for the treatment of Alzheimer's disease. Frontiers in Aging Neuroscience 2014;6(275);1-12.

89. Jasper HH. Report of the Committee on Methods of Clinical Examination in Electroencephalography. Electroenceph. Clin. Neurophysiol 1958;10: 370-1.

90. Laurin D, et al. Physical activity and risk of cognitive impairment and dementia in elderly persons. Arch Neurol 2001;58:498-504.

91. Li G, et al. A three-year follow-up study of age-related dementia in an urban area of Beijing. ActaPsychiatricaScandinavica 1991;83(2):99-104.

92. Toshitake $\mathrm{T}$, et al. Incidence and risk factors of vascular dementia and Alzheimer's disease in a defined elderly Japanese population: the Hisayama study. Neurology 1996;45:1161-1168.

93. Heyn P, Abreu B, Ottenbacher KJ. The effects of exercise training on elderly persons with cognitive imparment and dementia: a meta-analysis. Arch Phys Med Rehabil 2004;85:1694-1704.

94.Kramer AF, Kirk El, Colcombe SJ. Exercise, cognition, and the aging brain. J ApplPhysiol 2006;101:1237-1242.

95. Banissy, MJ; Muggleton, NG. Transcranial direct current stimulation in sports training: potential approaches. Frontiers in Human Neuroscience 2013;7(129):1-3.

96. Boggio, PS; et al. Enhancement of non-dominant hand motor function by anodal transcranial direct current stimulation. NeurosciLett 2006;404(1-2):232-236.

97. Hummel, FC; et al. Effects of brain polarization on reaction times and pinch force in chronic stroke. BMC Neurosci 2006;7(1):73.

98. Cogiamanian, F; et al. Improved isometric force endurance after transcranial direct current stimulation over the human motor cortical areas. Eur $\mathrm{J}$ Neurosci 2007;26(1):242-249.

99.Tanaka, S; et al. Single session of transcranial direct current stimulation transiently increases knee extensor force in patients with hemiparetic stroke. Neurorehabilitation and neural repair 2011;25(6):565-569.

100. Okano, AH; et al. Brain stimulation modulates the autonomic nervous system, rating of perceived exertion and performance during maximal exercise. $\mathrm{Br} \mathrm{J}$ Sports Med 2015;49:1213-1218. 
101. Moreau, D; Chun-Hao W; Tseng P; Chi-Hung J. Blending transcranial direct current stimulations and physical exercise to maximize cognitive improvement. Frontiers in Psychology 2015;6(678):1-5.

102. Montiel JM, et al. Evaluation of Montreal cognitive assessment for the differential diagnosis of mild cognitive impairment and Alzheimer's disease in elderly patients with more than 5 years of schooling: data from a Brazilian sample. Advances in Aging Research. 2013;2(4):121-129.

103. Cecato JF, et al. A subtest analysis of the Montreal cognitive assessment (MoCA): which subtests can best discriminate between healthy controls, mild cognitive impairment and Alzheimer's disease? International Psychogeriatrics. 2015; 1:1-8.

104. Cecato, JF; Montiel, JM; Bartholomeu, D; Martinelli, JE. Poder preditivo do MoCa na avaliação neuropsicológica de pacientes com diagnóstico de demência. RevBrasGeriatrGerontol2014;17(4):707-719.

105. Gorestein, C. et al. Psychometric properties of the Portuguese version of the Beck Depression Inventory on Brazilian college students. J ClinPsychol1999;55(5):553-62.

106. Gorestein, C; Andrade, L. Beck Depression Inventory: psychiometricproperties of the Portuguese version. Rev PsiqClin 1998;25:245-50.

107. Gorestein, C; Andrade, L. Validation of a Portuguese version of the Beck Depression Inventory and the State-Trait Anxiety Inventory in Brazilian subjects. Braz J Med Biol Res 1996;29(4):453-7.

108. Beck, AT; et al. An inventory for measuring depression. Arch Gen Psychiatry 1961;4:561-71.

109. Wechsler D. Wechsler adult intelligence scale-III. Nova York: PsychologicalCorporation; 1997.

110. Orsini A, Pasquadibisceglie M, Picone L. Factors which influence the difficulty of the spatial path in Corsi Block-Tapping Test. Perceptual Motor Skills 2001;200:732-738.

111. Nasseri, P; Nitsche, MA; Ekhtiari, H. A framework for categorizing electrode montages in transcranial direct current stimulation. Frontiers in Human Neuroscience 2015;9(54):1-5. 
112. Panico F, Sagliano L, Grossi D, Trojano L. Cerebellar cathodaltDCS interferes with recalibration and spatial realignment during prism adaptation procedure in healthy subjects. Brain Cogn. 2016;105:1-8.

113. van Elk M, Duizer M, Sligte I, van Schie $H$. Transcranial direct current stimulation of the right temporoparietal junction impairs third-person perspective taking. Cogn Affect BehavNeurosci. 2016.

114. Zwissler B, et al. Shaping memory accuracy by left prefrontal transcranial direct current stimulation. J Neurosci. 2014;34(11):4022-6.

115. Steenbergen L, et al. "Unfocus" on foc.us: commercial tDCS headset impairs working memory. ExpBrain Res. 2016;234(3):637-43.

116. Hanley JR, Young AW, Pearson NA. Impairment of the visuo-spatial sketch pad. Q J ExpPsychol A. 1991;43(1):101-25.

117. Nemmi F, Boccia M, Piccardi L, Galati G, Guariglia C. Segregation of neural circuits involved in spatial learning in reaching and navigational space. Neuropsychologia. 2013;51(8):1561-70.

118. Duncan J, Owen AM. Common regions of the human frontal lobe recruited by diverse cognitive demands. Trends Neurosci. 2000;23(10):475-83.

119. luculano $\mathrm{T}$, Kadosh RC. The mental cost of cognitive enhancement. J Neurosci. 2013;33(10):4482-4486. 


\title{
ANEXO A - TERMO DE APROVAÇÃO DO COMITÊ DE ÉTICA EM PESQUISA DA FACULDADE DE CIÊNCIAS DA SAÚDE DA UNIVERSIDADE DE BRASILIA
}

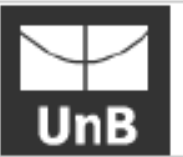

\author{
FACULDADE DE CIÊNCIAS DA \\ SAÚDE DA UNIVERSIDADE DE \\ BRASÍLIA - CEP/FS-UNB
}

\section{PARECER CONSUBSTANCIADO DO CEP}

\section{DADOS DO PROJETO DE PESQUISA}

Título da Pesquisa: Estimulação Transcraniana por Corrente Direta em Idosos com Comprometimento Cognitivo Leve

Pesquisador: Aline Simões de Alencastro

Área Temática:

Versäo: 3

CAAE: 53483516.8 .0000 .0030

Instituiçäo Proponente: FACULDADE DE SAÚDE - FS

Patrocinador Principal: Financiamento Próprio

\section{DADOS DO PARECER}

Número do Parecer: 1.546 .528

\section{Apresentação do Projeto:}

A expectativa de vida da população mundial vem crescendo rapidamente, mas está associada à prevalência de doenças crônicas como a demência. Atualmente a população com mais de 60 anos aproxima-se de 900 milhões de pessoas. O número de casos de pessoas com deméncia em 2015 (1) é de 46,8 milhões, ao passo que em 2012 o número era de 36 milhões.(2) Estima-se que a prevalência de demência em 2030 chegará a 74,7 milhöes em 2030 e 131,5 milhões em 2050. Estas novas estimativas estäo 12-13\% mais altas do que os números apresentados no World Alzheimer Report de 2009.(1) O impacto econômico da doença, consequentemente, é alto, tendo em 2010, um custo global de 604 bilhões de dólares e atualmente 818 bilhões de dólares, o que correspondente a mais de $1 \%$ do PIB global.(1, 2) Independente da etiologia, todas as demências, incluindo o comprometimento cognitivo leve (CCL), afetam progressivamente as habilidades cognitivas, comportamentais e funcionais. A limitação

nas atividades de vida diária compromete as habilidades funcionais e aumenta o risco de mortalidade, o que resulta em sobrecarga aos pacientes, familiares e à saúde pública e interfere diretamente na qualidade de vida.(3) O comprometimento cognitivo leve representa o período de transição entre o envelhecimento humano normal e o precoce diagnóstico de provável doença de Alzheimer (DA).(4) O diagnóstico de CCL pode ser realizado através do histórico do indivíduo $e$

\begin{tabular}{|c|c|}
\hline $\begin{array}{l}\text { Endereço: Faculdade de Clendas da Saude } \\
\text { Bairro: Asa Norte } \\
\text { UF: DF Municiplo: BRAsIUA } \\
\text { Telefone: (61)3107-1947 }\end{array}$ & $\begin{array}{l}\text { CEP: } 70.910-900 \\
\text { E-mall: ceofsunbegmal.com }\end{array}$ \\
\hline
\end{tabular}




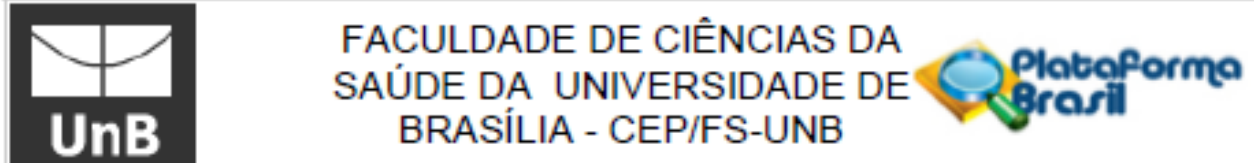

Continusplo do Parecer. 1.546 .528

\begin{tabular}{|c|c|c|c|c|}
\hline Infraestrutura & termoConcordancia_.jpeg & $\begin{array}{c}17 / 02 / 2016 \\
21: 33: 53 \\
\end{array}$ & $\begin{array}{l}\text { Aline Simóes de } \\
\text { Alencastro }\end{array}$ & Aceito \\
\hline Outros & LattesAlineAlencastro.pdf & $\begin{array}{c}21 / 01 / 2016 \\
21: 44: 06\end{array}$ & $\begin{array}{l}\text { Aline Simōes de } \\
\text { Alencastro }\end{array}$ & Aceito \\
\hline Outros & LattesJoaquimPereiraBrasilNeto.pdf & $\begin{array}{c}21 / 01 / 2016 \\
21: 43-28 \\
\end{array}$ & \begin{tabular}{|l} 
Aline Simöes de \\
Alencastro
\end{tabular} & Aceito \\
\hline Orçamento & Orcamentodetalhado $x \mid 5 x$ & $\begin{array}{c}21 / 01 / 2016 \\
21: 09-28 \\
\end{array}$ & $\begin{array}{l}\text { Aline Simōes de } \\
\text { Alencastro }\end{array}$ & Aceito \\
\hline Folha de Rosto & FolhaDeRosto2016.docx & $\begin{array}{c}20 / 01 / 2016 \\
19: 17: 13\end{array}$ & $\begin{array}{l}\text { Aline Simóes de } \\
\text { Alencastro }\end{array}$ & Aceito \\
\hline $\begin{array}{l}\text { Projeto Detalhado I } \\
\text { Brochura } \\
\text { Investigador }\end{array}$ & PROJETOCEPFS2016.docX & $\begin{array}{c}20 / 01 / 2016 \\
19: 05: 55\end{array}$ & $\begin{array}{l}\text { Aline Simóes de } \\
\text { Alencastro }\end{array}$ & Aceito \\
\hline $\begin{array}{l}\text { TCLE / Termos de } \\
\text { Assentimento / } \\
\text { Justificativa de } \\
\text { Auséncia }\end{array}$ & TCLE2016final.doc $x$ & $\begin{array}{c}06 / 01 / 2016 \\
23: 22: 30\end{array}$ & $\begin{array}{l}\text { Aline Simōes de } \\
\text { Alencastro }\end{array}$ & Aceito \\
\hline
\end{tabular}

Situação do Parecer:

Aprovado

Necessita Apreciação da CONEP:

Näo

BRASILIA, 16 de Maio de 2016

Assinado por:

Keila Elizabeth Fontana

(Coordenador)

Endereço: Faculdade de Cienclas da Saude - Campus Darcy Fubeiro

CEP: $70.910-900$

Telefone: (61)3107-1947

E-mall: ceptsunbggmal.com 


\title{
ANEXO B - TERMO DE CONSENTIMENTO LIVRE E ESCLARECIDO - TCLE
}

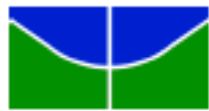

Pág. 1 de 2

\author{
Universidade de Brasilia
}

Faculdade de Ciências da Saúde

Programa de Pós-Graduação em Ciências da Saúde

Mestrado

\section{Termo de Consentimento Livre e Esclarecido - TCLE}

Convidamos o(a) Senhor(a) a participar do projeto de pesquisa Estimulação Transcraniana por Corrente Direta em Idosos com Comprometimento Cognitivo Leve, sob a responsabilidade da pesquisadora Aline Simões de Alencastro. O projeto utilizará uma técnica conhecida como "estimulação transcraniana por corrente direta", que utiliza uma pequena corrente elétrica, quase imperceptivel, aplicada sobre dois pontos do crânio, durante 20 minutos de cada vez.

O objetivo desta pesquisa é verificar se a utilização da estimulação transcraniana por corrente direta em uma única sessão interfere na memória dos pacientes com diagnóstico de comprometimento cognitivo leve. Isso significa leves problemas de memónia.

$O$ (a) senhor(a) receberá todos os esclarecimentos necessánios antes e no decorrer da pesquisa e the asseguramos que seu nome não aparecerá, sendo mantido o mais rigoroso sigilo pela omissão total de quaisquer informações que permitam identificálo(a).

A sua participação se dará por meio de testes, questionários e uma estimulação com eletrodos na cabeça que inicialmente o(a) senhor(a) poderá sentir um leve formigamento, mas desaparecerá com o decorrer da estimulação. $\mathrm{O}_{5}$ encontros ocorrerão no Laboratónio de Neurociências e Comportamento no Instituto de Biologia da Universidade de Brasilia na data combinada com um tempo estimado de 1 hora e 30 minutos em dois encontros para sua realização.

Os riscos decorrentes de sua participação na pesquisa são: uma possivel vermelhidão no local da aplicação dos eletrodos sobre a pele do crânio, que pode ser evitada, na maior parte dos casos, com o uso de soro físiológico nos contatos dos eletrodos com a pele durante a aplicação, e uma leve dor de cabeça imediatamente após a aplicação, que geralmente não necessita de medicação, mas que responde bem a analgésicos comuns (paracetamol, aspirina ou dipirona). Caso o senhor(a) sinta dor de cabeça nos informe para que a medicação the seja formecida. Se o(a) senhor(a) aceitar participar, estará contribuindo para o desenvolvimento de uma potencial nova modalidade de tratamento para pessoas com problemas de memónia.

$O$ (A) Senhor(a) pode se recusar a responder (ou participar de qualquer procedimento) qualquer questão que lhe traga constrangimento, podendo desistir de participar da pesquisa em qualquer momento sem nenhum prejuizo para o(a) senhor(a). Sua participação é voluntária, isto é, não há pagamento por sua colaboração.

Todas as despesas que o(a) senhor(a) tiver relacionadas diretamente ao projeto de pesquisa (por exemplo, exames para realização da pesquisa) serão cobertas pelo pesquisador responsável.

Caso haja algum dano direto comprovadamente decorrente de sua participação na pesquisa, o(a) senhor(a) poderá ser indenizado, obedecendo-se as disposições legais vigentes no Brasil. 


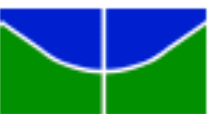

\section{Universidade de Brasília}

Faculdade de Ciências da Saúde

Programa de Pós-Graduação em Ciências da Saúde

\section{Mestrado}

Os resultados da pesquisa serão divulgados na Universidade de Brasilia podendo ser publicados posteriormente. Os dados e materiais serão utilizados somente para esta pesquisa e ficarão sob a guarda do pesquisador por um período de cinco anos, após isso serão destruídos.

Se o(a) Senhor(a) tiver qualquer dúvida em relação à pesquisa, por favor telefone para: Aline Simões de Alencastro, no telefone (61) 9367-5135, a ligação pode ser a cobrar e em qualquer horário. Não deixe de tirar suas dúvidas e informar qualquer sintoma.

Este projeto foi Aprovado pelo Comitê de Ética em Pesquisa da Faculdade de Ciências da Saúde (CEP/FS) da Universidade de Brasilia. O CEP é composto por profissionais de diferentes áreas cuja função é defender os interesses dos participantes da pesquisa em sua integridade e dignidade e contribuir no desenvolvimento da pesquisa dentro de padrões éticos. As dúvidas com relação à assinatura do TCLE ou os direitos do participante da pesquisa podem ser obtidos através do telefone: (61) 3107 1947 ou do e-mail cepfs $a$ unb.br ou cepfsunb $@$ gmail.com, horário de atendimento de $10: 00 \mathrm{hs}$ às $12: 00 \mathrm{hs}$ e de $13: 30 \mathrm{hs}$ às $15: 30 \mathrm{hs}$, de segunda a sexta-feira.

Este documento foi elaborado em duas vias, uma ficará com o pesquisador responsável e a outra com o Senhor(a).

Nome:

Assinatura

Aline Simões de Alencastro

Brasilia, de de 


\section{ANEXO C - FICHA DE INFORMAÇÕES DEMOGRÁFICAS E CLÍNICAS}

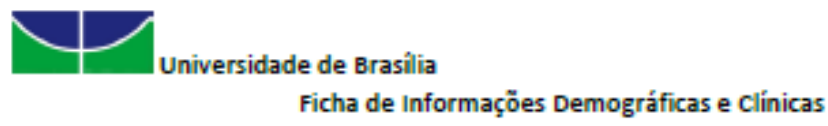

Pesquisador:

Data

1. Iniciais do Nome

2. Nome Completo:

3. Data de Nascimento: 4. Idade (anos completos):

5. Cidade de Nascimento:

(1) Brasília/DF

(2) Outra, qual:

6. Sexo: (0) Feminino

(1) Masculino

7. Tempo de escolaridade: anos ( $>=8$ anos=ensino fundamental)

8. Profissão:
(1) Näo tem
(2) Do Lar
(3) Aposentado
(4) Outra, qual:

9. Atividade Profissional: (descrever o motivo)

(1) Ativo. Tempo:

(2) Inativo por:

(3) Afastado por:

(4) Aposentado por:

10. Estado civil: (1)Solteiro

(2) Casado ou em União estável

(3) Separado

(4) Viưvo

11. Número de filhos:(1) Tem, quantidade:
(2) Não tem filhos

12. Com quem reside:

(1) Reside só

(2) Família conjugal com filhos

(3) Família conjugal sem filhos

(4) Parentes ou amigos

13. Tem problemas de visão: (1)Não:

(2)Sim:__qual: _Tem óculos: sim__ não:

14. Tem problemas de audição:

(1)กão:

(2)Sim: ___ Tem aparelho auditivo: sim___ não:

15. Tem problemas de motricidade:

(1)Não

16. Qual sua mão dominante: (1) direita. (2) esquerda. (3)ambas meses

17. Problemas neurológicos: (1)Näo.

(2)Sim, qual: Tempo:

(+) pessoal: (+) familiar: ,parentesco 
Universidade de Brasília

18. Diagnóstico de alguma doença:(*) ( ) AvC ( )TCE ( )Epilepsia ( )Diabetes

19.1. Tempo que apresenta adoença:

19. Medicação em uso:(*)

Dosagem:

Tempo de uso:

20. Faz uso de algum medicamento para dormir ou relaxar?(1)Não: 21.1.Qual:

21. Histórico Familiar (acontecimentos significativos):

22. Pratica Atividade Física:(1)Não: (2) sim:

Descrição de Atividade

Desde quando:

Frequência:

23. Pratica de alguma Atividade de Lazer:(curso de idioma, informática, artesanato...)

(1) Näo: (2) $\mathrm{sim}$

Descrição de Atividade

Desde quando:

Frequência:

24. Uso de computador ou smartphone (Compras, banco, jogos etc):(1)Não: Descrição de Atividade

Frequência:

25. Consumo álcool:(1)Não: _ (2) Sim:

Quanto em média:

Frequência:(*)

26. Consumo drogas:(1)Näo (2) Sim:

Quanto em média

Frequência: $\left({ }^{*}\right)$

27. É fumante:(1)Não: (2) $\operatorname{sim}$

Quanto em média: Frequência:

28. Consumo freqüente de café, refrigerante, chocolate ou alguma bebidaenergética:

(1) Não: (2) $\operatorname{sim}$ : Quanto?

29. Ingeriu cafeína hoje? (café, coca-cola, chá preto, chá mate,...)

(1) Não: (2) $\operatorname{sim}$

30. Observações ou comentários complementares (acontecimentos relevantes prévios ao estudo): 


\section{ANEXO D - MONTREAL COGNITIVE ASSESSMENT (MOCA)}

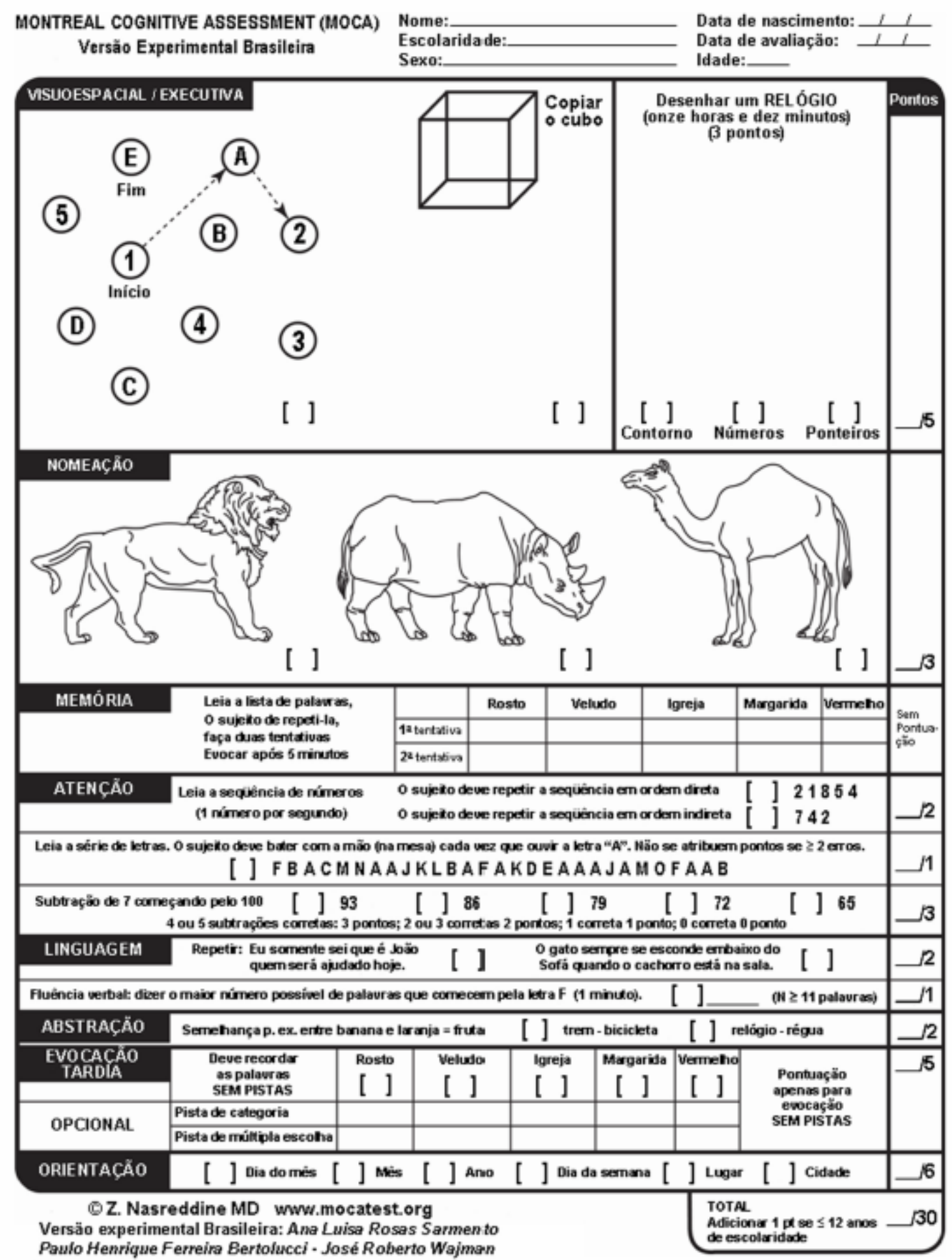
(UNIFESP.SP 2007) 


\title{
ANEXO E - INVENTÁRIO DE DEPRESSÃO DE BECK
}

\author{
Inventário de Depressão de Beck
}

Este questionário consiste em 21 grupos de afirmações. Depois de ler cuidadosamente cada grupo, faça um círculo em torno do número $(0,1,2$ ou 3) diante da afirmação, em cada grupo, que descreve melhor a maneira como você tem se sentido nesta semana, incluindo hoje. Se várias afirmaçôes num grupo parecerem se aplicar igualmente bem, faça um círculo em cada uma. Tome o cuidado de ler todas as afirmações, em cada grupo, antes de fazer a sua escolha.

1. 0 Não me sinto triste.

1 Eu me sinto triste.

2 Estou sempre triste e não consigo sair disso.

3 Estou tão triste ou infeliz que não consigo suportar.

2. 0 Não estou especialmente desanimado quanto ao futuro.

1 Eu me sinto desanimado quanto ao futuro.

2 Acho que nada tenho a esperar.

3 Acho o futuro sem esperança e tenho a impressão de que as coisas não podem melhorar.

3. 0 Não me sinto um fracasso. 1 Acho que fracassei mais do que uma pessoa comum.

2 Quando olho para trás, na minha vida, tudo o que posso ver é um monte de fracassos.

3 Acho que, como pessoa, sou um completo fracasso.

\section{0 Tenho tanto prazer em tudo} como antes.

1 Não sinto mais prazer nas coisas como antes.

2 Não encontro um prazer real em mais nada.

3 Estou insatisfeito ou aborrecido com tudo.

\author{
5. 0 Não me sinto especialmente \\ culpado. \\ 1 Eu me sinto culpado às vezes. \\ 2 Eu me sinto culpado na maior parte \\ do tempo. \\ 3 Eu me sinto sempre culpado.
}

6. 0 Não acho que esteja sendo punido.

1 Acho que posso ser punido.

2 Creio que vou ser punido.

3 Acho que estou sendo punido.

7. 0 Não me sinto decepcionado comigo mesmo.

1 Estou decepcionado comigo mesmo.

2 Estou enojado de mim.

3 Eu me odeio.

8. 0 Não me sinto de qualquer modo pior que os outros.

1 Sou crítico em relação a mim devido a minhas fraquezas ou meus erros.

2 Eu me culpo sempre por minhas falhas.

3 Eu me culpo por tudo de mal que acontece.

9. 0 Não tenho quaisquer idéias de me matar.

1 Tenho idéias de me matar, mas não as executaria.

2 Gostaria de me matar.

3 Eu me mataria se tivesse oportunidade.

10. 0 Não choro mais que o habitual. 1 Choro mais agora do que costumava.

2 Agora, choro o tempo todo.

3 Costumava ser capaz de chorar, mas agora não consigo mesmo que o queira. 
11. 0 Não sou mais irritado agora do que já fui.

1 Fico molestado ou irritado mais facilmente do que costumava.

2 Atualmente me sinto irritado o tempo todo.

3 Absolutamente não me irrito com as coisas que costumavam irritar-me.

12. 0 Não perdi o interesse nas outras pessoas.

1 Interesso-me menos do que costumava pelas outras pessoas.

2 Perdi a maior parte do meu interesse nas outras pessoas.

3 Perdi todo o meu interesse nas outras pessoas.

13.0 Tomo decisões mais ou menos tão bem como em outra época. 1 Adio minhas decisões mais do que costumava.

2 Tenho maior dificuldade em tomar decisões do que antes.

3 Não consigo mais tomar decisões.

14. 0 Não sinto que minha aparência seja pior do que costumava ser.

1 Preocupo-me por estar parecendo velho ou sem atrativos.

2 Sinto que há mudanças

permanentes em minha aparência que me fazem parecer sem atrativos. 3 Considero-me feio.

15. 0 Posso trabalhar mais ou menos tão bem quanto antes.

1 Preciso de um esforço extra para começar qualquer coisa.

2 Tenho de me esforçar muito até fazer qualquer coisa.

3 Não consigo fazer nenhum trabalho.

16. 0 Durmo tão bem quanto de hábito.

1 Não durmo tão bem quanto costumava.

2 Acordo uma ou duas horas mais cedo do que de hábito e tenho dificuldade para voltar a dormir. 3 Acordo várias horas mais cedo do que costumava e tenho dificuldade para voltar a dormir.
17. 0 Não fico mais cansado que de hábito.

1 Fico cansado com mais facilidade do que costumava.

2 Sinto-me cansado ao fazer quase qualquer coisa.

3 Estou cansado demais para fazer qualquer coisa.

18. 0 Meu apetite não está pior do que de hábito.

1 Meu apetite não é tão bom quanto costumava ser.

2 Meu apetite está muito pior agora.

3 Não tenho mais nenhum apetite.

19. 0 Não perdi muito peso, se é que perdi algum ultimamente.

1 Perdi mais de $2,5 \mathrm{Kg}$.

2 Perdi mais de $5,0 \mathrm{Kg}$.

3 Perdi mais de $7,5 \mathrm{Kg}$.

Estou deliberadamente tentando perder peso, comendo menos: SIM ( ) NÂO ( )

20. 0 Não me preocupo mais que o de hábito com minha saúde. 1 Preocupo-me com problemas físicos como dores e aflições ou perturbações no estômago ou prisão de ventre.

2 Estou muito preocupado com problemas físicos e é difícil pensar em outra coisa que não isso. 3 Estou tão preocupado com meus problemas físicos que não consigo pensar em outra coisa.

21. 0 Não tenho observado qualquer mudança recente em meu interesse sexual.

1 Estou menos interessado por sexo que costumava.

2 Estou bem menos interessado em sexo atualmente.

3 Perdi completamente o interesse por sexo 
ANEXO F - SEQUENCIA DE NÚMEROS E LETRAS

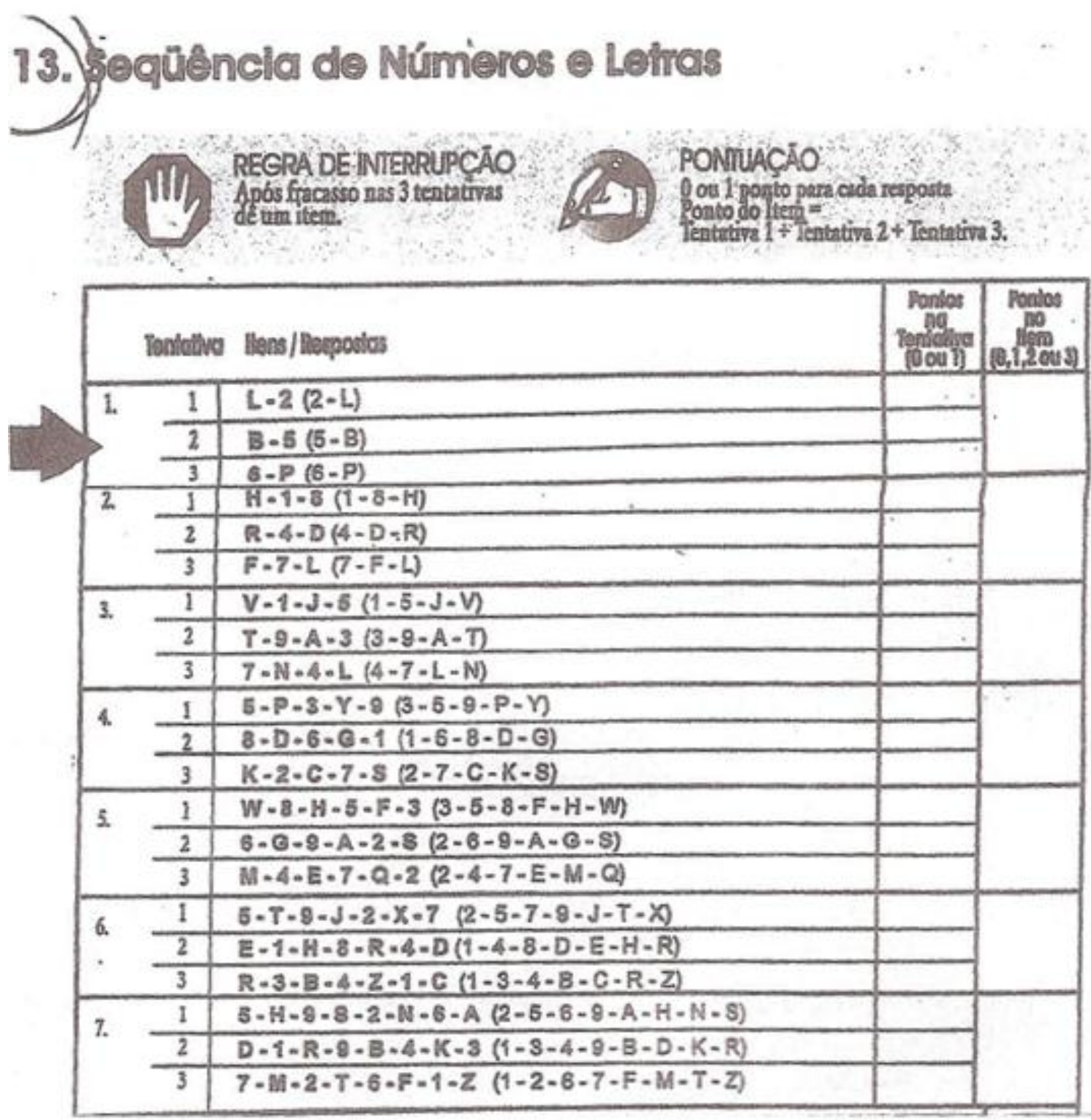




\section{ANEXO G - TESTE DOS CUBOS DE CORSI}

AVISO: Este material é indicado para profissionais treinados e bem orientados para a finalidade de avaliação. Consiste em um material-síntese que NÄO substitui a correta consulta às referências e normas adequadas e atualizadas. A avaliação consiste na aplicação da tarefa, conforme instruções apropriadas e correta interpretação. Consulte sempre as normas e documentos-referência.

\section{TESTE DOS CUBOS DE CORSI}

CONSTRUTO AVALIADO: Alcance da memória de curto prazo utilizando a alça visioespacial [de Paula et. al., 2010].

INSTRUÇÕES: "Eu irei tocar os cubos numa seqüência determinada neste tabuleiro. Quando eu terminar, quero que você os toque na mesma ordem. Depois disso, prosseguirei com outra seqüência. As seqüências serão gradualmente aumentadas".

Caso o participante comece a tarefa antes do examinador terminar, o mesmo deve dizer: "Por favor, espere até que eu termine".

SEQUÊNCIAS [Kessels at. al., 2000]:

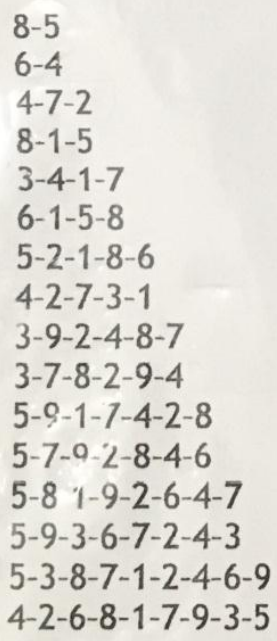

6-4

$4-7-2$

$8-1-5$

$3-4-1-7$

6-1-5-8

$5-2-1-8-6$

4-2-7-3-1

$3-9-2-4-8-7$

$3-7-8-2-9-4$

$5-9-1-7-4-2-8$

$5-7-9-2-8-4-6$

$5-8$ 1-9-2-6-4-7

5-9-3-6-7-2-4-3

5-3-8-7-1-2-4-6-9

4-2-6-8-1-7-9-3-5 
CRITÉRIO DE INTERRUPÇÃO: O teste é encerrado se o individuo falhar em duas seqüências de mesma extensão.

COTAÇÃO: A cotação é realizada pelo número de seqüências de blocos repetidas corretamente. Auto-correções são permitidas.

\section{REFERÊNCIAS:}

KESSELS, R. P. C. et. al. (2000). The Corsi Block-Tapping Task: Standardization and Normative Data. Applied Neuropsychology, vol. 7, n. 4. pp. 252 - 258.

BARON, I. S. (2004). Neuropsychological evaluation of the child. New York: Oxford University Press.

LEZAK, M. D. (1995). Neuropsychological assessment. ( $3^{\mathrm{a}}$. ed.). New York: Oxford University Press.

de PAULA, J. J. et. al. (2010). Propriedades psicométricas de um protocolo neuropsicológico breve para uso em populações geriátricas. Revista de Psiquiatria Clínica; 37 (6). pp. 246 - 250. 


\section{Transcranial direct current stimulation in mild cognitive impairment: methodology for a randomized controlled trial}

Background: Transcranial direct current stimulation (tDCS) is a non-invasive neuromodulatory technique that has shown encouraging results regarding performance improvement of normal subjects in tests of executive functions. Moreover, when applied repeatedly in daily sessions, tDCS has shown therapeutic potential in various neuropsychiatric disorders. However, there is a need for double-blind, placebo-controlled studies to determine the true therapeutic potential of this portable, low-cost and noninvasive treatment. Mild cognitive impairment (MCl) of the amnestic subtype may evolve into Alzheimer's dementia (AD) and pharmacological approaches have not been successful in ameliorating symptoms or halting progression to $A D$. Here we propose a protocol for studying a possible role for tDCS on improvement of $\mathrm{MCl}$ symptoms in older patients. Methods/Design: This will be a double-blind, placebo-controlled study of the effects of anodal tDCS over the left dorsolateral prefrontal cortex of patients with $\mathrm{MCl}$. Patients aged 60-90 years will be randomly assigned to either real tDCS or sham stimulation. Twentyminute real or sham tDCS sessions, 5 days a week, will be performed over the course of two weeks. The Rivermead Behavioural Memory Test (RBMT), California Verbal Learning Test, Rey Verbal Auditory Learning Test (RVALT) and Digit Span (WAIS-IV) will be assessed at baseline, after the first and second weeks of treatment, as well as one and three months after the last tDCS session. The primary outcome will be change in test scores over time. Secondary outcomes will be self-reported memory improvement and possible side effects of tDCS. Discussion: This study will evaluate possible therapeutic applications of tDCS for treatment of $\mathrm{MCl}$. tDCS is a portable and low-cost neuromodulatory technique that has been found to increase performance of both normal subjects and patients in many cognitive tasks. It will also examine the tolerability, program adherence and possible side effects of this novel technique in this age group. The information obtained in this study 
should be useful in planning further studies in which tDCS could be combined with other treatment modalities, such as cognitive training. 


\section{Transcranial direct current stimulation in mild cognitive impairment: methodology for a randomized controlled trial}

Aline S Alencastro ${ }^{1 * \dagger}$, Danilo A Pereira ${ }^{2}$ and Joaquim P Brasil-Neto ${ }^{1}$

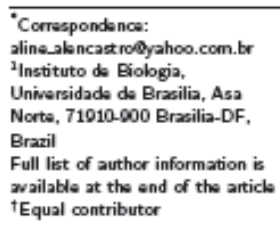

tEqual contributor the article

\begin{abstract}
Background: Transcranial direct current stimulation (tDCS) is a non-invasive neuromodulatory technique that has shown encouraging results regarding performance improvement of normal subjects in tests of executive functions. Moreover, when applied repeatedly in daily sessions, tDCS has shown therapeutic potential in various neuropsychiatric disorders. However, there is a need for double-blind, placebo-controlled studies to determine the true therapeutic potential of this portable, low-cost and non-invasive treatment. Mild cognitive impairment $(\mathrm{MCl})$ of the amnestic subtype may evolve into Alzheimer's dementia (AD) and pharmacological approaches have not been successful in ameliorating symptoms or halting progression to $A D$. Here we propose a protocol for studying a possible role for tDCS on improvement of $\mathrm{MCl}$ symptoms in older patients.

Methods/Design: This will be a double-blind, placebo-controlled study of the effects of anodal tDCS over the left dorsolateral prefrontal cortex of patients with $\mathrm{MCl}$. Patients aged $60-90$ years will be randomly assigned to either real tDCS $\alpha$ sham stimulation. Twenty-minute real or sham tDCS sessions, 5 days a week, will be performed over the course of two weeks. The Rivermead Behavioural Memory Test (RBMT), California Verbal Learning Test, Rey Verbal Auditory Learning Test (RVALT) and Digit Span (WAIS-IV) will be assessed at baseline, after the first and second weeks of treatment, as well as one and three months after the last tDCS session. The primary outcome will be change in test scores over time. Secondary outcomes will be self-reported memory improvement and possible side effects of tDCS.

Discussion: This study will evaluate possible therapeutic applications of tDCS for treatment of $\mathrm{MCl}$. tDCS is a portable and low-cost neuromodulatory technique that has been found to increase performance of both normal subjects and patients in many cognitive tasks. It will also examine the tolerability, program adherence and possible side effects of this novel technique in this age group. The information obtained in this study should be useful in planning further studies in which tDCS could be combined with other treatment modalities, such as cognitive training.

Trial registration:

Keywords: mild cognitive dysfunction; dementia; transcranial direct current stimulation; tDCS
\end{abstract}

\section{Background}

Life expectancy of the world population has been rapidly increasing, but has also been linked to a higher prevalence of chronic diseases such as dementia. Nowadays 
the population over 60 years old is near 900 million. The number of dementia cases in 2015 [1] is 46.8 million, whereas in 2012 this number was 36 million [2]. It is estimated that the prevalence of dementia will reach 74.7 million in 2030 and 131.5 million in 2050. These estimates are 12-13\% higher than those presented by the World Alzheimer Report of 2009 [1]. The economic impact of the disease, therefore, is high, and in 2010 its overall cost was 604 billion dollars, and at this time it has already reached 818 billion dollars, or more than $1 \%$ of the global GDP. Every dementia, regardless of its etiology, progressively affects cognitive, behavioral and functional abilities. Limitations in everyday life activities compromise functional abilities and increase the risk of fatal accidents and constitute a burden to the patient, family members and public health care facilities, directly impacting the quality of life [3].

Mild cognitive impairment is thought to represent a transitional period between normal ageing and the diagnosis of clinically probable very early Alzheimer's disease (AD) [4]. The diagnosis of MCI can be done by taking a history and performing a mental status exam, possibly complemented with neuropsychological testing [5].

Several attempts have been made at developing a pharmaoological treatment to ameliorate symptoms or to decrease the rate of progression of dementia of the Alzheimer type, but so far no drug has achieved this goal [6]. Recently, a nonpharmacological, non-invasive neuromodulatory technique, namely repetitive transcranial magnetic stimulation (TMS), has been found to improve memory in both normal volunteers and older patients with mild cognitive impairment (MCI) [7]. Good results have also been reported concerning memory and language in patients with mild Alzheimer's disease when TMS was administered together with cognitive training [8].

TMS is able to induce electric currents in the cerebral parenchyma, acoording to Faraday's Law [9]. The effects of electric currents upon neuronal function have been studied for decades [10]. More recently, after several reports of beneficial effects of TMS upon symptoms of many neuropsychiatric disorders, such as depression [11] and chronic pain [12], transcranial direct current stimulation (tDCS) has also been the subject of many studies due to its ability to modulate cortical function in a non-invasive manner. For that reason, there is a great deal of interest in its potential applications in the fields of neurology and psychiatry [13]. tDCS employs direct current to modulate neuronal excitability according to the polarity of stimulation: anodal stimulation has been found to increase neuronal excitability, whereas cathodal stimulation decreases excitability of the underlying cortical region [14]. The technique of tDCS is not new [10], but the interest in it has just recently been renewed, after decades of oblivion. This was due to new discoveries in the field of neurcescience, including the development of TMS [9].

Many studies are currently under way to explore possible applications of tDCS in the treatment of neuropsychiatric disorders; in one of those clinical trials, anodal tDCS has been performed in post-stroke aphasia with good results [15]. In patients with Alzheimer's disease, anodal stimulation has led to improvements in declarative memory [14].

Especially noteworthy, however, are the results obtained in normal subjects: tDCS to specific cortical areas has been shown to increase memory and learning. The effects are not only present during the stimulation period, but usually persist for 
hours to days after the stimulation session [16]. Moreover, repeated tDCS sessions have been found to extend the benefit to weeks, or even months, in several neuropsychiatric disorders [13].

Although both TMS and tDCS show promise as potential non-pharmacological treatments for many neuropsychiatric disorders, $t D C S$ is especially interesting due to its simplicity, low cost and portability. Thus, in view of the recent demonstration of beneficial effects of TMS in patients with MCI [7], it would be interesting to verify whether tDCS would be able to produce similar results. MCI may be divided into amnestic and non-amnestic subtypes [6]. The amnestic subtype strongly predisposes the individual toward Alzheimer's disease [6]. Here we propose a study protocol to test for possible effects of anodal tDCS sessions targeting the left dorsolateral prefrontal cortex on memory of patients with the amnestic subtype of MCI. Since anodal stimulation increases cortical excitability, the rationale would be the same as that of applying high-frequency rTMS to the same cortical region, as in the study by Marra et al [7].

The primary aim of this randomised controlled trial is to determine the effectiveness of 10 sessions of anodal left prefrontal cortex stimulation in improving everyday memory in patients with the amnestic subtype of MCL. In addition, patients will be retested at 1 and 3 months to verify the duration of any beneficial effects.

\section{Methods}

\section{Design}

A prospective, randomized controlled trial will be conducted with 80 communitydwelling participants with a diagnosis of MCI.

\subsection{Participant selection}

To be included in the study participants must meet the following inclusion criteria: (i) diagnosis of MCI; (ii) aged 60 to 90 years; (iii) educational level of 4 or more school years; (iv) duration of MCI symptoms of at least one year.

Participants will be excluded if they take any drugs acting on the central nervous system, if they have a history of neurological disorders, or if focal neurological deficits are present at examination.

\subsection{Screening tests}

1.2.1 Cognitive

All subjects will be tested for depression using the 17-item Hamilton Depression (HAMD-17) Scale [17], since depression can be a confounding factor in the diagnosis of MCI. The Clinical Dementia Rating (CDR) [18], Mini-Mental State Examination2:EV (MMSE) [19] and the Philadelphia Brief Assessment of Cognition (PBAC) [20] will also be assessed. To evaluate everyday memory and its possible improvement with tDCS the Rivermead Behavioural Memory Test (RBMT)[21][7], California Verbal Learning Test (CVLT) [22], Rey Verbal Auditory Learning Test (RVALT) [23] and Digit Span (WAIS-IV) [24] will be employed. 
1.2.2 Medical and laboratory tests

All subjects will undergo a neurological examination and blood will be drawn for lab tests to exclude clinical secondary causes of dementia or cognitive deficits, such as hypothyroidism, AIDS, vitamin B12 and folate deficiency, and syphilis. Brain MRI scans will be obtained to exclude focal or lacunar ischemia, brain tumors, and hydrocephalus. Table 1 details the planned assessment schedule.

\subsection{Randomization}

After completion of the initial assessment, participants will be formally entered into the study and randomized to intervention or control group. Randomization will be done using computer-generated random numbers and will be performed by an investigator not involved in patient assessments. The same investigator will perform real and sham tDCS sessions.

\subsubsection{Intervention group}

The intervention group will undergo ten daily sessions of anodal tDCS targeting the left dorsolateral prefrontal cortex, five days a week, for two weeks.

Stimulation will be delivered by a custom-made, battery-driven, direct current stimulator through electrodes embedded in sponges (area: $35 \mathrm{~cm} 2$ ) soaked with $\mathrm{NaCl}$ $0.9 \%$. The anode will placed over F3 (10-20 EEG electrode positioning system) and the cathode over the contralateral supraorbital region. Current intensity will be kept at $1.5 \mathrm{~mA}$ and stimulation duration will be $20 \mathrm{~min}$.

\subsubsection{Control group}

Patients in the control (sham) group will undergo the same procedure as the intervention group, but the current will be tapered off over 5 seconds after the initial 10 seconds ramp-up period. This maneuver will provide the subjects with the same initial tingling sensation experienced during a real tDCS session, but with no physiological effects [25].

\subsection{Cognitive testing}

Patients will undergo The Rivermead Behavioural Memory Test (RBMT) before the first tDCS session (baseline), after the first and second weeks of tDCS and at one and three months after treatment.

\section{Outcome measures}

The primary outcome measure will be RBMT scores. Secondary outcome measures will be the patient's self-reported memory improvement, if any, and complaints of poesible tDCS side effects, as well as perception of having been subject to the real or to the sham procedure.

\section{Statistical analysis}

A two-way ANOVA will be used to compare test scores at baseline (T0), after 5 and 10 tDCS sessions (T1 and T2, respectively), and after 1 and 3 months posttreatment (T3 and T4). Student's t test will be used to compare baseline mean scores for the intervention and control groups. Besides frequentist analysis, we also 
take advantage of Bayesian statistics to maximize information retrieval and poesibly minimize the length of the trial and the number of patients studied in case of efficacy of the intervention [26].

\section{Sample power estimation}

Although Bayesian statistics may allow for a reduction in the required number of patients [26], a preliminary estimation of such number has been made. The sample size has been estimated with using GPower 3.1 [27]. Measurements will be evaluated comparing the RBMT test performance across time and intervention groups. The potential effect size of anodal tDCS sessions upon performance in the RBMT has been estimated from the findings of a previously published work in which MCI patients underwent 10 sessions of rTMS [7]. Thirty subjects in each group will be required to achieve a power of 0.8 in detecting improvements with intervention. Taking into acoount the dropout rate of $25 \%, 40$ participants per arm should be recruited.

\section{Discussion}

tDCS has been able to improve performanoe of normal subjects in learning and memory tasks [16]. It remains to be seen whether patients with MCI would benefit from such an approach.

The effects of tDCS tend to be relatively non-focal, but neurons actively engaged in a given task seem to be more prone to its effects, i.e., it is possible to achieve a certain degree of functional focalization by applying tDCS in conjunction with cognitive tasks. In fact, tDCS-linked working-memory has been found to provide long-term benefits in maintaining cognitive training benefits and extending them to untrained tasks in healthy older adults [28]. However, in a study with Alzheimer's patients, adding anodal tDCS to memory training did not result in a synergistic effect [29]. In this regard, it is noteworthy that a protocol for studying the effects of tDCS combined with cognitive training in patients with mild $\mathrm{AD}$ has been recently published [30]. However, the authors intend to stimulate the left temporal cortex rather than the left dorsolateral prefrontal cortex. The great variability in tDCS montages, intensity of stimulation and targeted cortical areas across studies has hampered progress in its clinical application. Therefore, it is important that study protocols be published to allow a more efficient discussion of paradigms, aiming at improving study comparability.

Should the present study demonstrate a beneficial effect of tDCS sessions upon RBMT scores in MCI patients, a study using the same stimulation paradigm combined with cognitive training would be warranted.

Competing interests

The authors declare that they have no compering interests.

Authors' contributions

ASA and JPB conceived the idea for the protocol. All authors contributed to the design and development of the trial protocol. ASA and JPB drafted the manuscript. All authors critically reviened an approved the final wersion of the manuscript.

Author details

Instituto de Biologia, Universidade de Brasilia, Asa Norte, 71010-000 Brasiliz-DF, Brazil. ${ }^{2}$ Instituto Brasileiro de Neuropsicologia o Ciśncias Cognitivas, CRS 504, Bloco C, Entr. 37, 1 andar, Asa Su, 70331-535 Brasilia-DF, Brazil 


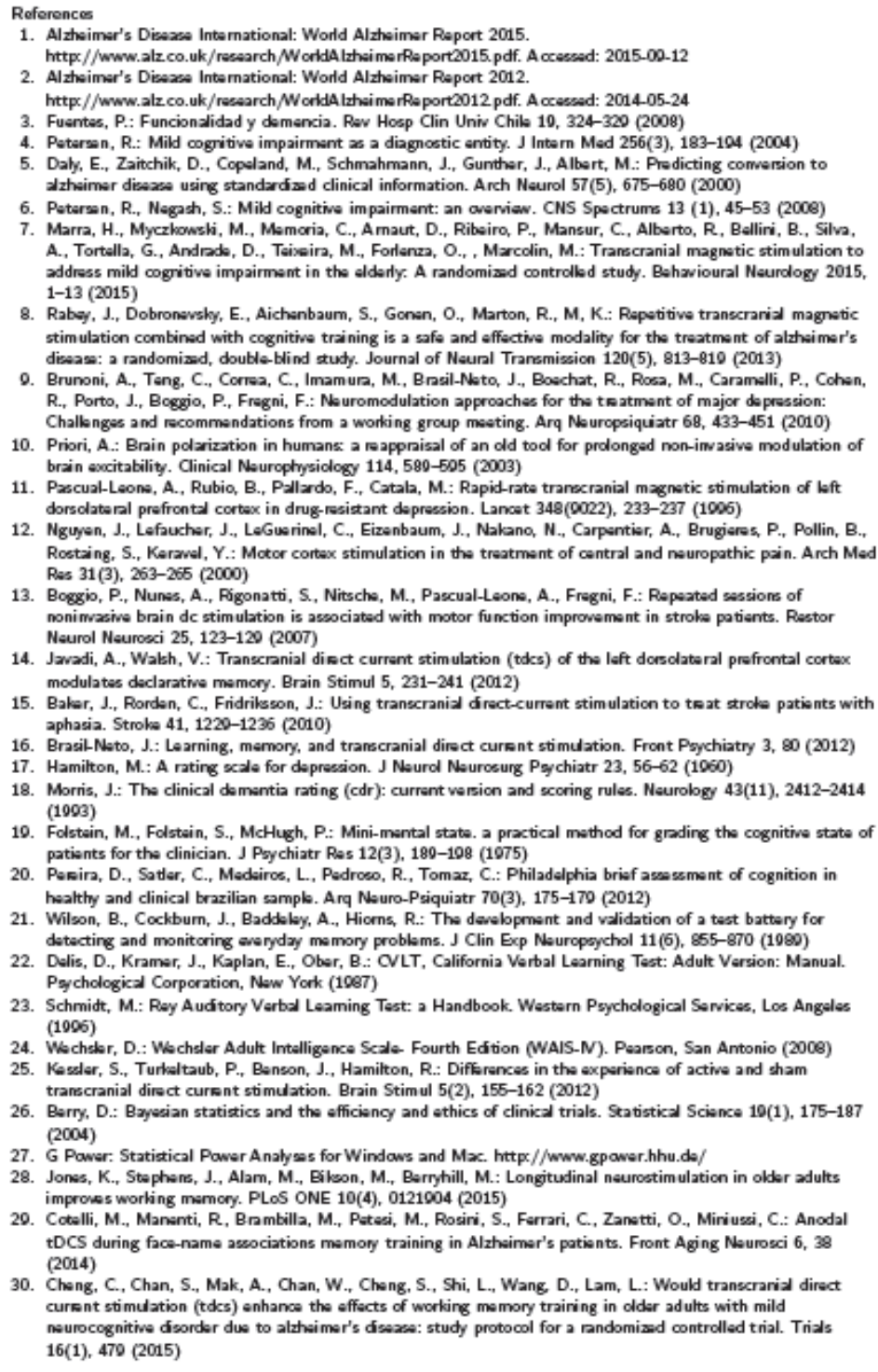


Table 1 Assessment schedule.

\begin{tabular}{|c|c|c|c|c|c|}
\hline & Baseline (TO) & First week (T1) & Second week (T2) & One Month (T3) & Three Months (T4) \\
\hline Neurological exam & $\mathrm{x}$ & & & & \\
\hline Blood tests & $\mathbf{x}$ & & & & \\
\hline MRI & $\mathbf{x}$ & & & & \\
\hline CDR & $\mathbf{x}$ & & & & \\
\hline HAMD-17 & $\mathrm{x}$ & & $\mathbf{x}$ & $\mathbf{x}$ & $\mathbf{x}$ \\
\hline MMSE-2:EV & $\mathbf{x}$ & $\mathbf{x}$ & $\mathbf{x}$ & $\mathbf{x}$ & $\mathbf{x}$ \\
\hline PBAC & $\mathbf{x}$ & $\mathbf{x}$ & $\mathbf{x}$ & $\mathbf{x}$ & $\mathbf{x}$ \\
\hline CVLT & $\mathbf{x}$ & $\mathbf{x}$ & $\mathbf{x}$ & $\mathrm{x}$ & $\mathbf{x}$ \\
\hline RVALT & $\mathbf{x}$ & $\mathbf{x}$ & $\mathbf{x}$ & $\mathbf{x}$ & $\mathbf{x}$ \\
\hline Digit Span & $\mathbf{x}$ & $\mathbf{x}$ & $\mathbf{x}$ & $x$ & $\mathrm{x}$ \\
\hline RBMT & $\mathrm{x}$ & $\mathrm{x}$ & $\mathrm{x}$ & $\mathrm{x}$ & $\mathrm{x}$ \\
\hline
\end{tabular}

